\title{
Chapter 2 \\ Design of High Alloy Austenitic CrMnNi Steels Exhibiting TRIP/TWIP Properties
}

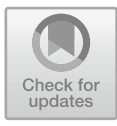

\author{
Qiuliang Huang, Marco Wendler, Javad Mola, Andreas Weiß, Lutz Krüger \\ and Olena Volkova
}

\begin{abstract}
This chapter is centered on the development of austenitic high strength cast CrMnNi steels with excellent strength-ductility combination by triggering TWIP and TRIP effects. Special attention is given to obtain a high yield strength and a good formability. For this purpose, three generations of steels were developed. The $1^{\text {st }}$ generation is comprised of cast X3CrMnNi16-7-X steels. Their Ni concentration was varied in order to manipulate the stacking fault energy of austenite and change the operative deformation mechanisms. Based on the mechanical properties of the $1^{\text {st }}$ generation steels, the $2^{\text {nd }}$ generation steels were developed with a composition similar to the $\mathrm{X} 3 \mathrm{CrMnNi16-7-6}$ steel. Interstitial alloying elements were added to take advantage of solid solution strengthening and precipitation hardening effects. The substitutional alloy contents were carefully adjusted to ensure the occurrence of TRIP/TWIP effects during plastic deformation. For the $3^{\text {rd }}$ generation, two steels from the $2^{\text {nd }}$ generation, X16CrNiMnN15-3-3 and X16CrNiMnN19-4-3, were treated with tailored quenching and partitioning (Q\&P) processing routines to further increase
\end{abstract}

\footnotetext{
Q. Huang $(\varangle) \cdot$ M. Wendler $\cdot$ A. Weiß $\cdot$ O. Volkova

Institute of Iron and Steel Technology, TU Bergakademie Freiberg, Freiberg, Germany

e-mail: qhuang@iest.tu-freiberg.de
}

M. Wendler

e-mail: marco.wendler@iest.tu-freiberg.de
A. Weiß
e-mail: weiss@iest.tu-freiberg.de
O. Volkova
e-mail: volkova@iest.tu-freiberg.de
J. Mola

Material Design and Structural Integrity Lab, Osnabrück University of Applied Sciences, Osnabrück, Germany

e-mail: j.mola@hs-osnabrueck.de

\section{Krüger}

Institute of Materials Engineering, TU Bergakademie Freiberg, Freiberg, Germany

e-mail: krueger@ww.tu-freiberg.de 
the strength, especially the yield strength. The developed Q\&P cast steels exhibited an outstanding strength-ductility combination, e.g. a yield strength over $1000 \mathrm{MPa}$ and a total elongation exceeding $20 \%$ for the steel X16CrNiMnN15-3-3 containing $0.12 \mathrm{wt} \% \mathrm{~N}$.

\subsection{Introduction}

Conventional austenitic stainless steels such as AISI 304 have been widely accepted in industry due to their outstanding properties such as superior toughness and extraordinary formability [1]. They are usually used in the annealed state and exhibit relatively low strength. Therefore, efforts have been made to develop metastable austenitic steels with low stacking fault energy (SFE) to enhance the strength-ductility combination by introducing transformation-induced and twinning-induced plasticity (TRIP and TWIP) effects during deformation of the steels [2-4].

To enable martensitic transformation at a certain temperature, the Gibbs free energy of martensite must be lower than that of austenite. The temperature, where the Gibbs free energies of the two phases are equal, is usually denoted as $T_{0}$ [5]. In practice, a sufficient undercooling below $T_{0}$ is often required to supply the interfacial energy between the austenite and the martensite nuclei as well as the elastic strain energy associated with the transformation [6]. Under external loading, deformation can proceed via martensitic transformation, twinning and other plasticity mechanisms. The occurrence of these mechanisms depends on the chemical composition and temperature, as they both influence the SFE [7-10]. It is commonly accepted that a SFE below $20 \mathrm{mJm}^{-2}$ favors the transformation of austenite into martensite by either the sequence $\gamma \rightarrow \varepsilon \rightarrow \alpha^{\prime}$ or direct $\gamma \rightarrow \alpha^{\prime}$ transformation $[11,12]$. The deformation-induced transformation to martensite is regarded to be responsible for the so-called TRIP effect [13].

When SFE increases to a value between 20 and $40 \mathrm{mJm}^{-2}$, the formation of mechanical twins is often observed [14]. The twins have different crystal orientations with respect to the matrix and hence, they reduce the effective glide distance of dislocations. The latter leads to an enhanced strain hardening, especially in the presence of a high twin density. This mechanism in TWIP steels is described as the dynamic Hall-Petch effect [15]. With an even higher SFE, where dissociation of perfect dislocations is energetically unfavorable, deformation proceeds mainly by the wavy glide of perfect dislocations [16]. It results in dislocation cell structures with almost dislocation-free interiors [17].

Decreasing SFE enhances the planar slip of dislocations, which promotes the formation of deformation bands with numerous stacking faults (SF) localized on parallel $\{111\}$ planes of austenite. At a given strain rate, the associated ductility increases significantly compared to steels with high SFE, where wavy glide serves as the dominant deformation mechanism [18]. Table 2.1 summarizes the temperature dependence of austenite SFE [19]. SFE can also be modified by careful adjustment of the alloy content. The $\mathrm{Cr}, \mathrm{Si}$, and $\mathrm{Mn}$ addition in $\mathrm{Fe}-\mathrm{Cr}-\mathrm{Ni}$ austenitic stainless steels 
Table 2.1 Variation of austenite SFE with temperature $\left(\mathrm{d} \gamma_{\mathrm{SF}} / \mathrm{d} T\right)$ [19]

\begin{tabular}{l|l|l|l}
\hline Alloys $(w t \%)$ & $\mathrm{d} \gamma_{\mathrm{SF}} / \mathrm{dT}\left(\mathrm{mJm}^{-2} \mathrm{~K}^{-1}\right)$ & Temperature range $\left({ }^{\circ} \mathrm{C}\right)$ & References \\
\hline $\mathrm{Fe}-18 \mathrm{Cr}-14 \mathrm{Ni}-4 \mathrm{Si}$ & 0.04 & $-123 \leq \mathrm{T} \leq 127$ & {$[7]$} \\
\hline $\mathrm{Fe}-18.3 \mathrm{Cr}-10.7 \mathrm{Ni}$ & 0.05 & $25 \leq \mathrm{T} \leq 325$ & {$[7,23]$} \\
\hline $\mathrm{Fe}-7.8 \mathrm{Cr}-12 \mathrm{Ni}$ & 0.05 & $-150 \leq \mathrm{T} \leq 100$ & {$[24]$} \\
\hline $\mathrm{Fe}-17.8 \mathrm{Cr}-14.1 \mathrm{Ni}$ & 0.06 & $-180 \leq \mathrm{T} \leq 27$ & {$[7,8]$} \\
\hline $\mathrm{Fe}-15.9 \mathrm{Cr}-12.5 \mathrm{Ni}$ & 0.08 & $-115 \leq \mathrm{T} \leq 100$ & {$[7,8]$} \\
\hline $\mathrm{Fe}-18.7 \mathrm{Cr}-16.9 \mathrm{Ni}$ & 0.10 & $25 \leq \mathrm{T} \leq 325$ & {$[7,23]$} \\
\hline $\mathrm{Fe}-18 \mathrm{Cr}-7 \mathrm{Ni}-0.18 \mathrm{C}$ & 0.10 & $20 \leq \mathrm{T} \leq 330$ & {$[7,25]$} \\
\hline $\mathrm{Fe}-19.9 \mathrm{Mn}-4 \mathrm{Cr}-0.48 \mathrm{C}$ & 0.08 & $27 \leq \mathrm{T} \leq 127$ & {$[26]$} \\
\hline
\end{tabular}

was found to lower SFE and promote the planar dislocation arrays, while the Ni and $\mathrm{C}$ alloying raises SFE and encourages a cellular dislocation arrangement [20]. There is no consensus regarding the effect of $\mathrm{N}$ on SFE. In an $\mathrm{Fe}-21 \mathrm{Cr}-6 \mathrm{Ni}-9 \mathrm{Mn}$ steel, SFE reduces from $53 \mathrm{mJm}^{-2}$ at $0.21 \mathrm{wt} \% \mathrm{~N}$ to $33 \mathrm{mJm}^{-2}$ at $0.24 \mathrm{wt} \% \mathrm{~N}$ [21]. Further increase in $\mathrm{N}$ content up to $0.52 \mathrm{wt} \%$ does not vary the SFE. In the $\mathrm{Fe}-18 \mathrm{Cr}-10 \mathrm{Mn}$ steel, on the contrary, SFE increases from $10 \mathrm{mJm}^{-2}$ at $0.39 \mathrm{wt} \% \mathrm{~N}$ to $23 \mathrm{mJm}^{-2}$ at $0.69 \mathrm{wt} \% \mathrm{~N}$ [22].

The present work focuses on developing CrMnNi cast stainless steels as the matrix for novel composite materials, TRIP-Matrix-Composites, for the Collaborative Research Center 799. Efforts, including varying the Ni content, addition of different interstitial contents, and application of tailored quenching and partitioning (Q\&P) processing routines, were made to achieve a high strength combined with a high ductility in the cast CrMnNi stainless steels.

\subsection{Experimental Methods}

The steels were all melted in a VIM12 vacuum induction melting and casting facility (ALD Vacuum Technologies $\mathrm{GmbH}$ ) and cast in water-cooled copper molds as illustrated in Fig. 2.1. Details about the production of the steels can be referred to [27-29].

Hollow specimens with a length of $10 \mathrm{~mm}$, an outer diameter of $4 \mathrm{~mm}$ and an inner diameter of $2 \mathrm{~mm}$ were used for dilatometry experiments on Bähr $805 \mathrm{~A} / \mathrm{D}$ dilatometer with a cryogenic unit, which enabled subzero quenching to $-130{ }^{\circ} \mathrm{C}$. The as-quenched $\alpha^{\prime}$-martensite fraction $\left(f_{\alpha^{\prime}}^{Q}\right)$ was determined by subtracting the $\delta$ ferrite fraction estimated by optical microscopy from the ferromagnetic phase fraction quantified by magnetic measurements. The latter was obtained based on the measured magnetization after corrections for the effect of alloying elements on the magnetization of pure iron. The accuracy is therefore dependent on the accuracy of the corrections for the effect of chemical composition and is usually within $\pm 1 \mathrm{vol} \%$. 

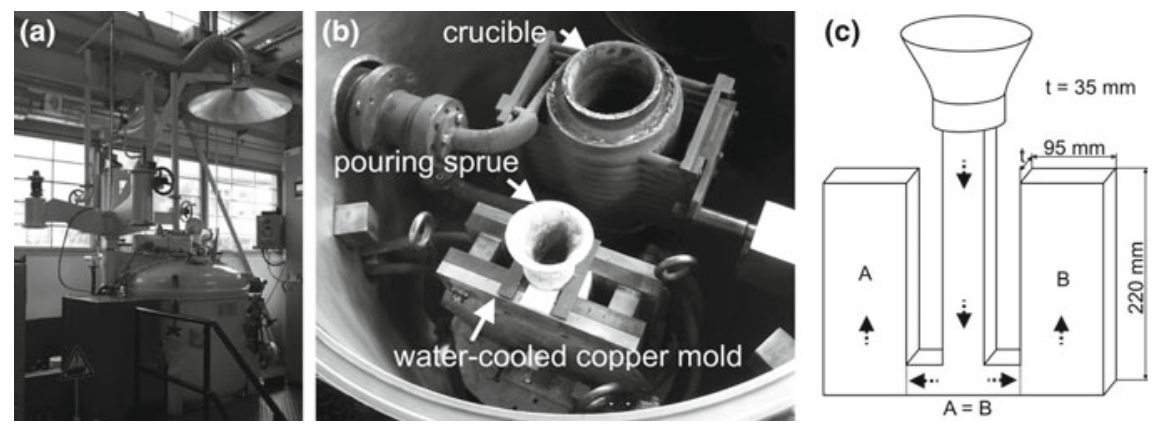

Fig. 2.1 a VIM 12 vacuum induction melting and casting facility used for the fabrication of the cast steels; b Components inside the furnace chamber; $\mathbf{c}$ Schematic view of the cast mold with arrows indicating the flow direction of the melt during casting [29]

The mechanical properties of the steels were evaluated by tensile testing on a Zwick 1476 universal testing machine at various temperatures. Tensile specimens with a gauge diameter of $6 \mathrm{~mm}$ and a gauge length of $30 \mathrm{~mm}$ were machined according to ISO 6892-1. The tensile direction was parallel to the height of ingots A and B in Fig. 2.1c. To minimize the adiabatic heating of tensile specimens, the crosshead displacement speed was set to $1 \mathrm{~mm} \mathrm{~min}^{-1}$. This corresponds to an initial strain rate of $4 \times 10^{-4} \mathrm{~s}^{-1}$. For each alloy, three specimens were tested at each temperature. Straininduced $\alpha^{\prime}$-martensite fraction $\left(f_{\alpha^{\prime}}^{\text {ind. }}\right)$ was determined by subtracting the $\alpha^{\prime}$-martensite fraction $\left(f_{\alpha^{\prime}}\right)$ in the undeformed grip section from the $\alpha^{\prime}$-martensite fraction in the uniformly-deformed gauge section. After $f_{\alpha^{\prime}}^{\text {ind. }}$ values at various testing temperatures

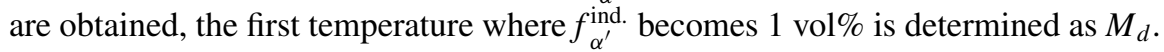

Besides optical microscope, microstructures were examined using a Zeiss ULTRA 55 GEMINI-type field emission scanning electron microscope (FESEM) equipped with an AMETEK-EDAX analysis system for chemical composition and elemental distribution analysis. The deformed microstructures were characterized by electron backscatter diffraction (EBSD) measurements and electron contrast channeling imaging (ECCI). The step size for EBSD examinations was $0.1-0.2 \mu \mathrm{m}$ and the camera (DIGIVIEW) output rate was 70 frames per second. ECCI was performed using an angle-selective backscatter electron detector (ASB) and a large aperture in the high current mode. The precipitation of carbides was verified by selected area electron diffraction (SAED) and Fast-Fourier Transformation (FFT) of highresolution images in a Jeol JEM-2200FS transmission electron microscope (TEM). Efforts were made to avoid martensitic transformation during sample preparation by grinding and polishing at $80{ }^{\circ} \mathrm{C}$ and final electropolishing. The fracture surfaces of tested tensile specimens were examined using the secondary electron (SE) detector at an acceleration voltage of $10 \mathrm{kV}$. 


\subsection{Austenitic CrMnNi Cast Steels}

For the $1^{\text {st }}$ generation steels, the SFE was modified by varying the $\mathrm{Ni}$ content in cast X3CrMnNi16-7 steels from 3 to $9 \mathrm{wt} \%$. Tensile testing at various temperatures reveals pronounced TRIP effect at RT in the cast steels with 3 and $6 \mathrm{wt} \% \mathrm{Ni}$.

\subsubsection{Constitution and Special Methods}

The chemical compositions of the $1^{\text {st }}$ generation $\mathrm{CrMnNi}$ steels are shown in Table 2.2. To determine martensite start $\left(M_{S}\right)$ temperatures, dilatometry cycles involving heating under vacuum to $1050{ }^{\circ} \mathrm{C}$ at $10 \mathrm{~K} / \mathrm{s}$ and cooling to $-130^{\circ} \mathrm{C}$ at $10 \mathrm{~K} / \mathrm{s}$ after a holding time of $30 \mathrm{~min}$ were performed [30]. Prior to tensile tests, tensile specimens were solution annealed at $1050{ }^{\circ} \mathrm{C}$ for 30 min under vacuum to reduce the compositional inhomogeneity of substitutional elements generated during solidification. Tensile tests were done at temperatures ranging from -196 to $250{ }^{\circ} \mathrm{C}$.

\subsubsection{Initial Microstructures of 16-7-3/6/9 Steels}

The microstructures of the cast steels were predicted based on Schaeffler diagram (Fig. 2.2) with $\mathrm{Cr}-$ and Ni-equivalents $\left(\mathrm{Cr}_{\mathrm{eq}}\right.$ and $\left.\mathrm{Ni}_{\mathrm{eq}}\right)$ calculated according to the following equations proposed for cast austenitic stainless steels [32]:

$$
\begin{gathered}
\mathrm{Cr}_{\mathrm{eq}}=\% \mathrm{Cr}+\% \mathrm{Mo}+4 \% \mathrm{Ti}+4 \% \mathrm{Al}+1.5 \% \mathrm{Si} \\
+1.5 \% \mathrm{~V}+0.9 \% \mathrm{Nb}+0.9 \% \mathrm{Ta}+0.5 \% \mathrm{~W} \\
\mathrm{Ni}_{\mathrm{eq}}=\% \mathrm{Ni}+30 \% \mathrm{C}+18 \% \mathrm{~N}+0.5 \% \mathrm{Mn} \\
+0.3 \% \mathrm{Co}+0.2 \% \mathrm{Cu}-0.2 \% \mathrm{Al}
\end{gathered}
$$

The microstructures and phase fractions of the cast steels are demonstrated in Fig. 2.3. With increasing Ni content, the fractions of $\alpha^{\prime}$-martensite and $\delta$-ferrite decrease until a fully austenitic microstructure is obtained for the $9 \% \mathrm{Ni}$ alloy. The SFE of the steels at RT is calculated according to the empirical relationship in (2.3)

Table 2.2 Chemical compositions of the $1^{\text {st }}$ generation CrMnNi steels in wt $\%$ [31]

\begin{tabular}{l|l|l|l|l|l|l|l}
\hline Steels & Steel ID & $\mathrm{Cr}$ & $\mathrm{Mn}$ & $\mathrm{Ni}$ & $\mathrm{Si}$ & $\mathrm{C}$ & $\mathrm{N}$ \\
\hline Cast X3CrMnNi16-7-3 & $16-7-3$ & 16.40 & 7.00 & 3.10 & 1.00 & 0.03 & 0.01 \\
\hline Cast X3CrMnNi16-7-6 & $16-7-6$ & 16.20 & 7.10 & 5.90 & 1.10 & 0.03 & 0.01 \\
\hline Cast X3CrMnNi16-7-9 & $16-7-9$ & 16.40 & 6.90 & 9.00 & 1.09 & 0.03 & 0.01 \\
\hline
\end{tabular}




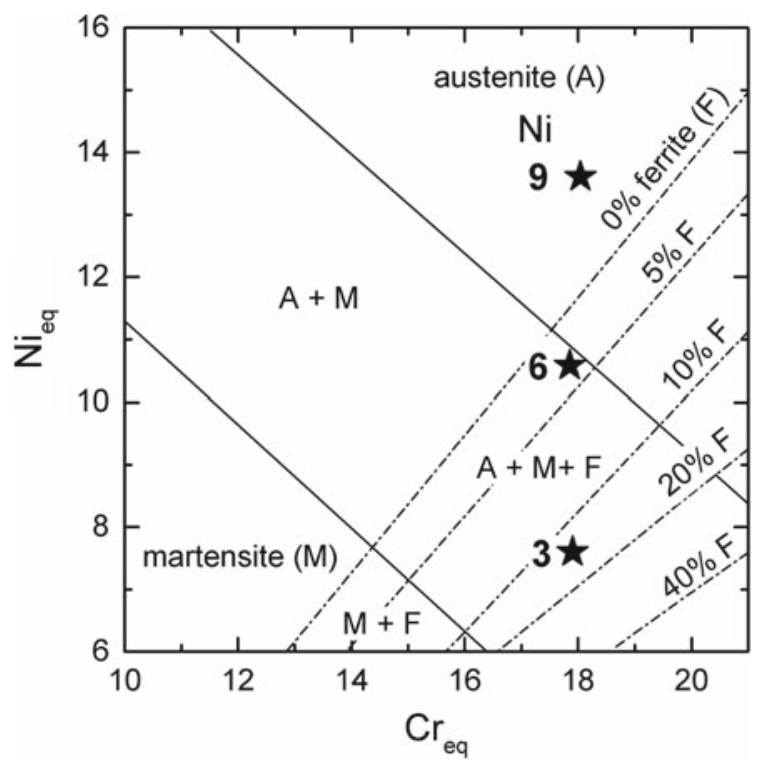

Fig. 2.2 Position of 16-7-3/6/9 steels in Schaeffler diagram based on (2.1)-(2.2)
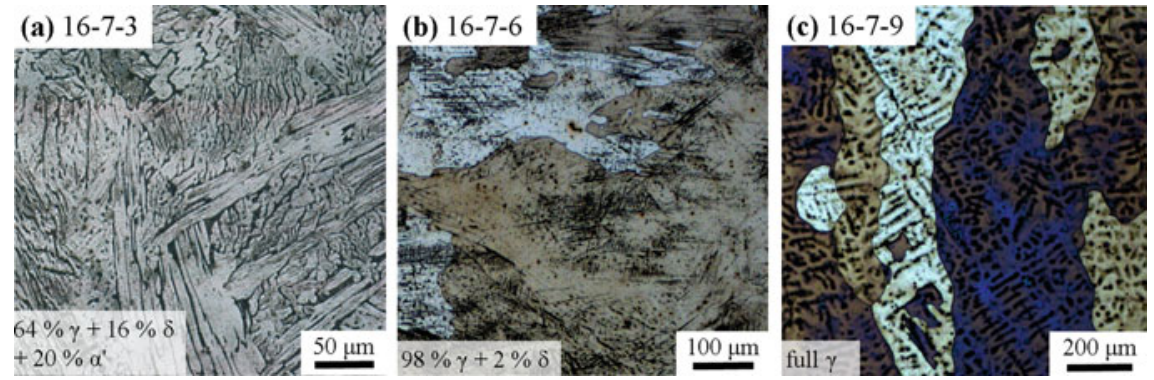

Fig. 2.3 Optical micrographs and phase fractions of the steels (a) 16-7-3, (b) 16-7-6 and (c) 16-7-9 solution annealed at $1050{ }^{\circ} \mathrm{C}$ for $30 \mathrm{~min}$. Note that the straight lines (black) in some austenitic regions of (b) represent deformation bands induced in the first solidified regions (dendrite cores) during the metallographic preparation. The depletion of alloying elements and the low stability of austenite in such regions may lead to the formation of preparation-induced martensite. The samples were etched with Beraha I solution [34]

[33]. The calculated SFEs and the $M_{s}$ temperatures determined using dilatometry are shown in Table 2.3.

$$
\begin{aligned}
\mathrm{SFE}= & 39+1.59 \% \mathrm{Ni}-1.34 \% \mathrm{Mn}+0.06 \% \mathrm{Mn}^{2}-1.75 \% \mathrm{Cr}+0.01 \% \mathrm{Cr}^{2} \\
& +15.21 \% \mathrm{Mo}-5.59 \% \mathrm{Si}+26.27(\% \mathrm{C}+1.2 \% \mathrm{~N})(\% \mathrm{Cr}+\% \mathrm{Mn}+\% \mathrm{Mo})^{1 / 2} \\
& +0.61[\% \mathrm{Ni}(\% \mathrm{Cr}+\% \mathrm{Mn})]^{1 / 2}-60.69(\% \mathrm{C}+1.2 \% \mathrm{~N})^{1 / 2}
\end{aligned}
$$




\subsubsection{Mechanical Properties of 16-7-3/6/9 Steels}

The stress-strain curves of the cast steels are indicated in Fig. 2.4. The associated mechanical properties and the $f_{\alpha^{\prime}}$ values are summarized in Fig. 2.5. Analogous to $M_{s}$ temperatures, $M_{d}$ temperatures calculated based on $f_{\alpha^{\prime}}^{\text {ind. in Fig. } 2.5 \mathrm{~d} \text { reduce }}$ with raised Ni contents $\left(120 \rightarrow 60 \rightarrow 30^{\circ} \mathrm{C}\right)$. With decreasing tensile test temperature from $250{ }^{\circ} \mathrm{C}$ to $M_{d}$ temperature the elongation increases (Fig. 2.5b) due to the reduced SFE, which promotes the propagation of SFs and restricts climb and cross slip of dislocations [35]. Below $M_{d}$ temperature, where strain-induced $\alpha^{\prime}$-martensite formation can be triggered, elongation decreases as a result of the early occurrence of $\alpha^{\prime}$-martensite during tensile tests and the accompanied obstruction of planar dislocation motion in the austenite. Intersection points of slip bands, SFs, $\varepsilon$-martensite and twins may act as nucleation sites for the strain-induced $\alpha^{\prime}$-martensite formation.

The elongation of the 16-7-9 steel decreases first below $20^{\circ} \mathrm{C}$ and then increases again when the temperature drops from -70 to $-196^{\circ} \mathrm{C}$. The latter increase is related to an attenuated $\alpha^{\prime}$-martensitic transformation below Néel temperature $\left(T_{\mathrm{N}}\right)$, which enhances the plasticity. The influence of $T_{\mathrm{N}}$ on $\alpha^{\prime}$-martensite formation is discussed in detail in Sect. 2.4.3.

Owing to the presence of a high $f_{\alpha^{\prime}}^{Q}$ in the undeformed condition, the 16-7-3 steel (Fig. 2.5d) exhibited almost always the smallest $f_{\alpha^{\prime}}^{\text {ind. }}$ (Fig. 2.5c) but the highest total $f_{\alpha^{\prime}}$ after tensile tests (Fig. 2.5d). This explains the higher ultimate tensile strength (UTS) of the 16-7-3 steel compared to 16-7-6 and 16-7-9 steels (Fig. 2.5a). The presence of $16 \mathrm{vol} \% \delta$-ferrite in the initial microstructure of the 16-7-3 steel might have also contributed to its higher strength as ferrite often offers a higher strength than austenite. In contrast, the fully austenitic 16-7-9 steel provides the lowest tensile strength.

At RT, the UTS and total elongation (TE) are $1013 \mathrm{MPa}$ and $23 \%$ for the 167-3 steel, $765 \mathrm{MPa}$ and 53\% for the 16-7-6 steel, and $550 \mathrm{MPa}$ and $72 \%$ for the 16-7-9 steel, respectively. Due to the higher Ni content and SFE of the 16-7-9 steel compared to the other two steels, the $\alpha^{\prime}$-martensitic transformation was almost fully suppressed during testing at RT. In contrast, a pronounced TRIP effect was observed in both 16-7-3 and 16-7-6 steels. The products of UTS and TE are 23.3, 40.5 and 39.6 GPa\% for the 16-7-3, 16-7-6, and 16-7-9 steels, respectively.

To examine the formability of steels at RT, an austenitic cast steel with a chemical composition similar to the 16-7-6 steel, namely X4CrMnNi16-7-7, was cold rolled in 22 passes to reduce the thickness from $14.3 \mathrm{~mm}$ to $0.7 \mathrm{~mm}$. The total reduction

Table 2.3 $M_{S}$ temperatures and SFE based on (2.3) for 16-7-3/6/9 steels [31]

\begin{tabular}{l|r|l}
\hline Steel ID & $M_{s}\left({ }^{\circ} \mathrm{C}\right)$ & SFE at RT $\left(\mathrm{mJm}^{-2}\right)$ \\
\hline $16-7-3$ & 61 & 10 \\
\hline $16-7-6$ & 1 & 16 \\
\hline $16-7-9$ & -47 & 22 \\
\hline
\end{tabular}


(a)

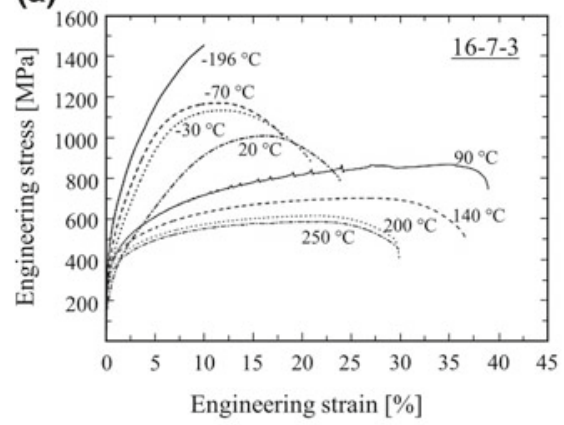

(b)

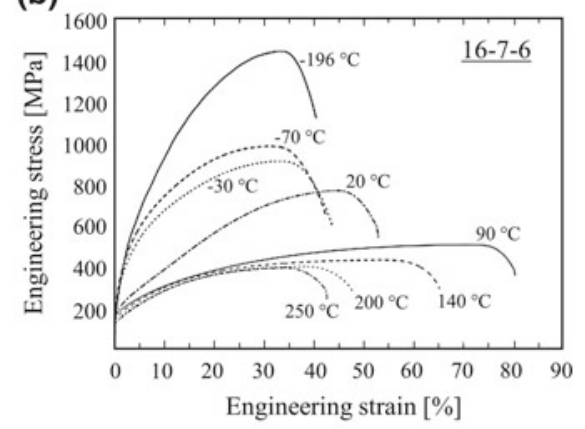

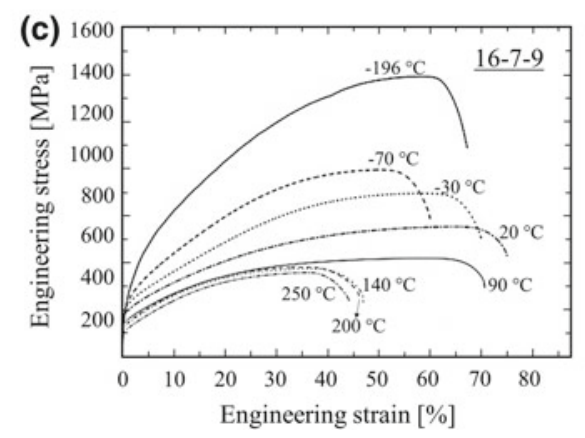

Fig. 2.4 Stress-strain curves of a 16-7-3, b 16-7-6, and c 16-7-9 steels tested at various temperatures [31]

ratio was $95 \%$. Between consecutive passes, the steel was allowed to cool down to RT. As shown in Fig. 2.6a, the TRIP effect occurred already in the second pass. After the final pass, 21 vol\% strain-induced $\alpha^{\prime}$-martensite was formed, which increased the hardness from 143 to $515 \mathrm{HV}$. In spite of its coarse cast dendritic microstructure, the ingot could be successfully rolled without any intermediate annealing.

The outstanding mechanical properties of the cast steels of the present study, regardless of their cast microstructure which is usually characterized by a coarse grain size and poor ductility [36], can be attributed to the low SFE of the steels ranging between 10 and $22 \mathrm{mJm}^{-2}$. At these SFE values, plastic deformation proceeds by planar glide of partial dislocations and may be aided by TRIP/TWIP effects. The formation of deformation bands, strain-induced $\alpha^{\prime}$-martensite and mechanical twins fragments the coarse cast structure and decreases the grain size of the initial austenite. They serve as obstacles to dislocation motion and hence, reduce the dislocation mean free path. The associated enhanced strain hardening postpones the necking of the material according to the Considère criterion. In this way, the drawback of a coarse cast structure is partly compensated. 

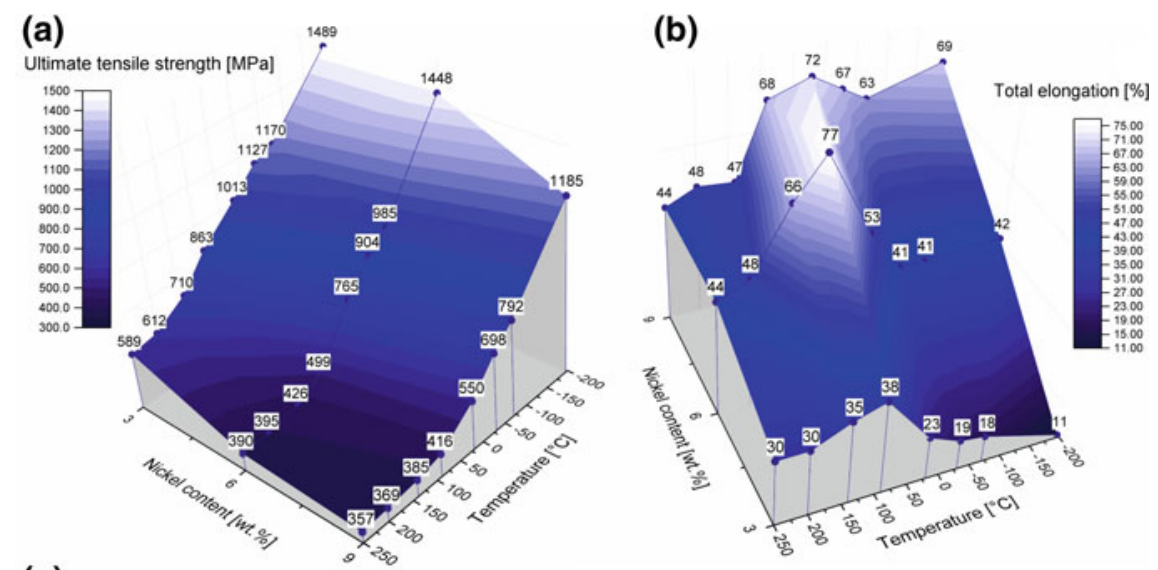

(c)
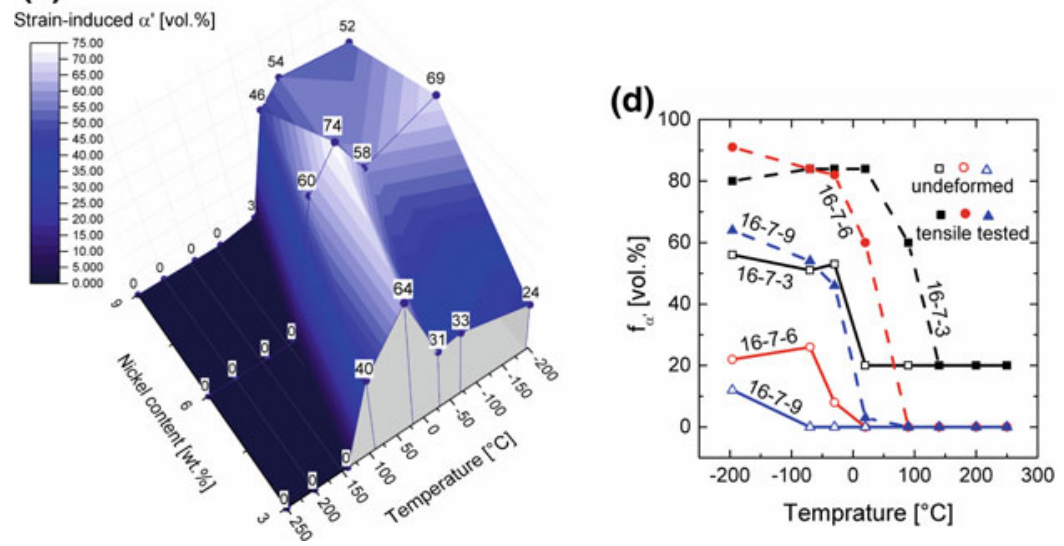

Fig. 2.5 a UTS, b TE, $\mathbf{c} f_{\alpha^{\prime}}^{\text {ind. }}$, and $\mathbf{d} f_{\alpha^{\prime}}^{Q}$ (open symbols) and total $f_{\alpha^{\prime}}$ after tensile tests (solid symbols) at various $\mathrm{Ni}$ contents and temperatures

\subsubsection{Conclusions for the $1^{\text {st }}$ Generation Steels}

The mechanical properties of the $1^{\text {st }}$ generation cast stainless steels consisting of $\mathrm{X} 3 \mathrm{CrMnNi} 16-7-3 / 6 / 9$ were investigated in the temperature range of -196 to $250{ }^{\circ} \mathrm{C}$. In general, all steels exhibited a tensile behavior typical for austenitic steels with deformation-induced plasticity mechanisms. At decreasing tensile temperatures, the tensile elongation increases to a peak value before it reduces at temperatures below $M_{d}^{\gamma \rightarrow \alpha^{\prime}}$. The temperature corresponding to the peak elongation decreases at higher $\mathrm{Ni}$ content. In addition, the grain fragmentation resulting from the formation of deformation bands, strain-induced $\alpha^{\prime}$-martensite and mechanical twins compensates the disadvantages of the coarse cast structures in the studied steels and results in their excellent mechanical properties at RT. 
(a)

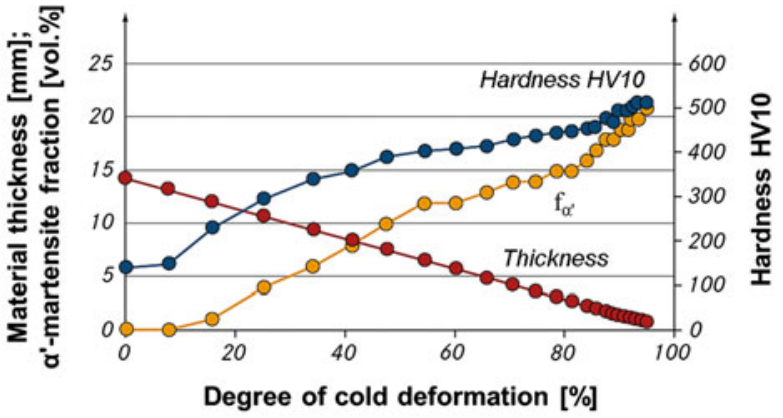

(b)

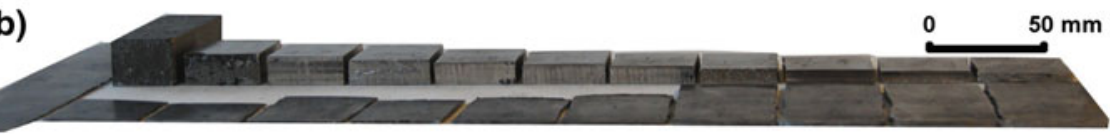

Fig. 2.6 a The variation in thickness, $f_{\alpha}{ }^{\prime}$ and hardness of an $\mathrm{X} 4 \mathrm{CrMnNi16-7-7}$ cast ingot during 22 passes of cold rolling; b Pictures showing thickness reduction during rolling [37]

\subsection{Austenitic CrMnNi-C-N Cast Steels}

Although the steels studied in the first period, especially 16-7-6, provide excellent strength-ductility combination, their strength level at RT remains low (below $1000 \mathrm{MPa}$ ). Therefore, the target for the $2^{\text {nd }}$ generation was to achieve a high strength, especially yield strength (YS), by the addition of interstitial alloying elements to make use of their solid solution strengthening effect as well as precipitation hardening by the formation of carbides, nitrides and carbo-nitrides. To counterbalance the austenite stabilizing effect of interstitial alloying, the substitutional contents were modified to facilitate the occurrence of TRIP effect during plastic deformation.

\subsubsection{Constitution and Special Methods}

Two series of steels with compositions shown in Tables 2.4 and 2.5 were produced. In both series, the $\mathrm{N}$ content is maintained nearly constant (target $\mathrm{N}$ contents of either $0.10 \mathrm{wt} \%$ in Series I and $0.15 \mathrm{wt} \%$ in Series II) while C contents are varied between 0.05 and $0.25 \mathrm{wt} \%$ in steps of $0.05 \mathrm{wt} \%$. To achieve high $\mathrm{N}$ contents of nearly $0.15 \mathrm{wt} \%$ in Series II, their Cr contents were raised to $19 \mathrm{wt} \%$ to increase the $\mathrm{N}$ solubility in the liquid steel [38]. In short, Series I steels with the designation $\mathrm{X}(0.05-0.25) \mathrm{CrNiMnN} 15-3-3$ are denoted as Cr15NC10.X and Series II steels with the designation $\mathrm{X}(0.05-0.25) \mathrm{CrNiMnN} 19-4-3$ are referred to as $\mathrm{Cr} 19 \mathrm{NC} 15 . \mathrm{X}$, where $\mathrm{X}$ indicates the $\mathrm{C}$ concentration in wt\% times hundred. The molten steels were cast in a copper mold with a cross section dimension of $95 \times 35 \mathrm{~mm}^{2}$. 
Table 2.4 Chemical compositions of interstitially-alloyed $\mathrm{X}(0.05-0.25)$ CrNiMnN15-3-3 steels in $\mathrm{wt} \%$ and the respective SFEs based on (2.1) [39]

\begin{tabular}{l|l|l|l|l|l|l|l|l}
\hline Steel & Steel ID & $\mathrm{Cr}$ & $\mathrm{Ni}$ & $\mathrm{Mn}$ & $\mathrm{Si}$ & $\mathrm{N}$ & $\mathrm{C}$ & $\mathrm{SFE}\left(\mathrm{mJm}^{-2}\right)$ \\
\hline $\begin{array}{l}\text { Cast } \\
\text { X5CrNiMnN15-3-3 }\end{array}$ & Cr15NC10.05 & 14.90 & 2.86 & 3.11 & 0.51 & 0.103 & 0.052 & 12 \\
\hline $\begin{array}{l}\text { Cast } \\
\text { X10CrNiMnN15-3-3 }\end{array}$ & Cr15NC11.10 & 15.20 & 2.89 & 3.20 & 0.48 & 0.107 & 0.100 & 14 \\
\hline $\begin{array}{l}\text { Cast } \\
\text { X16CrNiMnN15-3-3 }\end{array}$ & Cr15NC12.16 & 14.90 & 2.91 & 2.97 & 0.53 & 0.122 & 0.155 & 18 \\
\hline $\begin{array}{l}\text { Cast } \\
\text { X20CrNiMnN15-3-3 }\end{array}$ & Cr15NC11.20 & 15.10 & 3.23 & 2.99 & 0.49 & 0.106 & 0.200 & 20 \\
\hline $\begin{array}{l}\text { Cast } \\
\text { X25CrNiMnN15-3-3 }\end{array}$ & Cr15NC13.25 & 14.90 & 3.03 & 3.02 & 0.57 & 0.132 & 0.250 & 24 \\
\hline
\end{tabular}

Table 2.5 Chemical compositions of interstitially-alloyed X(0.05-0.25) CrNiMnN19-4-3 steels in wt $\%$ and the respective SFEs based on (2.1) [19]

\begin{tabular}{l|l|l|l|l|l|l|l|l}
\hline Steel & Steel ID & $\mathrm{Cr}$ & $\mathrm{Ni}$ & $\mathrm{Mn}$ & $\mathrm{Si}$ & $\mathrm{N}$ & $\mathrm{C}$ & $\mathrm{SFE}\left(\mathrm{mJm}^{-2}\right)$ \\
\hline $\begin{array}{l}\text { Cast } \\
\text { X5CrNiMnN19-4-3 }\end{array}$ & Cr19NC14.05 & 18.90 & 4.02 & 2.90 & 0.53 & 0.140 & 0.051 & 14 \\
\hline $\begin{array}{l}\text { Cast } \\
\text { X10CrNiMnN19-4-3 }\end{array}$ & Cr19NC15.10 & 19.20 & 3.97 & 3.09 & 0.53 & 0.149 & 0.097 & 17 \\
\hline $\begin{array}{l}\text { Cast } \\
\text { X16CrNiMnN19-4-3 }\end{array}$ & Cr19NC14.16 & 19.20 & 4.11 & 3.20 & 0.50 & 0.140 & 0.156 & 21 \\
\hline $\begin{array}{l}\text { Cast } \\
\text { X20CrNiMnN19-4-3 }\end{array}$ & Cr19NC16.21 & 19.30 & 4.09 & 3.15 & 0.54 & 0.162 & 0.208 & 26 \\
\hline $\begin{array}{l}\text { Cast } \\
\text { X25CrNiMnN19-4-3 }\end{array}$ & Cr19NC15.26 & 19.10 & 4.17 & 3.06 & 0.49 & 0.146 & 0.264 & 30 \\
\hline
\end{tabular}

The addition of interstitial elements inevitably introduces precipitates such as $\mathrm{M}_{23} \mathrm{C}_{6}$ carbides and $\mathrm{M}_{2} \mathrm{~N}$ nitrides ( $\mathrm{M}$ denotes $\mathrm{Fe}$ and $\mathrm{Cr}$ ) during cooling of the ingots. These precipitates would reduce the solute interstitial contents of steels. Hence, the steels were solution annealed at temperatures above their full dissolution points prior to the tensile tests. The full dissolution temperatures increase at higher interstitial contents as predicted by phase diagrams in Fig. 2.7. The applied solution annealing temperatures as marked in Fig. 2.7 were chosen based on the results obtained by dilatometry and Thermo-Calc. Annealing was performed for $30 \mathrm{~min}$ followed by water quenching to RT to suppress the re-formation of precipitates.

The influence of $T_{\mathrm{N}}$ temperature on the $\alpha^{\prime}$-martensite formation was investigated using Cr15NC10.X steels. $T_{\mathrm{N}}$ of the alloys were calculated by extrapolating the available thermodynamic database of Thermo-Calc version $\mathrm{S}$ [40] to temperatures below RT. The sensitivity of $T_{\mathrm{N}}$ to the $\mathrm{C}$ concentration was quite low. The calculated $T_{\mathrm{N}}$ temperatures were $-132{ }^{\circ} \mathrm{C}$ and $-128{ }^{\circ} \mathrm{C}$ for the steels $\mathrm{Cr} 15 \mathrm{NC} 13.25$ and $\mathrm{Cr} 15 \mathrm{NC} 10.05$, respectively. To determine the effect of the antiferromagnetic to paramagnetic transition of austenite at $T_{\mathrm{N}}$ on the formation of $\alpha^{\prime}$-martensite, solution annealed cylindrical specimens with a dimension of $\varnothing 6 \mathrm{~mm} \times 3.5 \mathrm{~mm}$ were 
quenched to temperatures between $-196{ }^{\circ} \mathrm{C}$ and RT and held for $10 \mathrm{~min}$. The spontaneous $\alpha^{\prime}$-martensite fractions were subsequently quantified by magnetic saturation measurements.

\subsubsection{Initial Cast Microstructures of the Steel Series}

The used ingot mold had a cross section of $95 \times 35 \mathrm{~mm}^{2}$ different from the $50 \times$ $50 \mathrm{~mm}^{2}$ employed for the $1^{\text {st }}$ generation steels. The increased contact area of the liquid steel with the mold, arising from the rectangular shape of the cross section, boosted the heat dissipation into the mold and resulted in the refinement of dendrites during solidification. As indicated in Fig. 2.8, the primary dendrite spacing of the cast ingots was significantly finer than those of the $1^{\text {st }}$ generation steels, leading to a less pronounced microsegregation of main alloying elements.

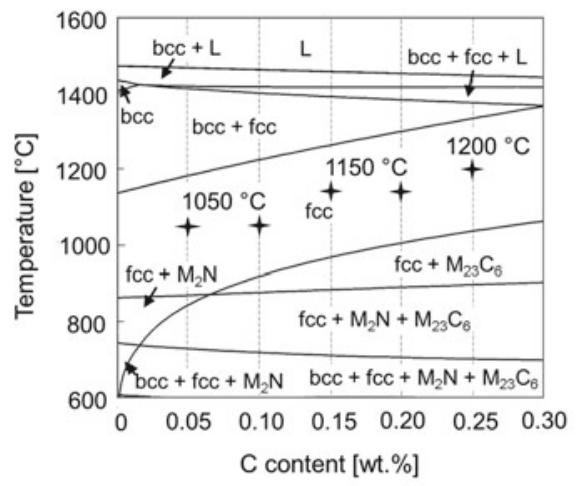

(a) $\mathrm{Cr} 15 \mathrm{NC10.X}$

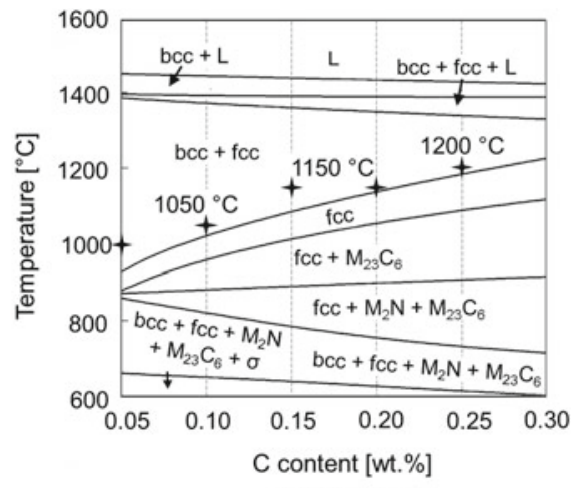

(b) Cr19NC15.X

Fig. 2.7 Phase diagrams of a Cr15NC10.X [39] and b Cr19NC15.X [19] steels. Symbols indicate solution annealing temperatures prior to tensile tests

(a)

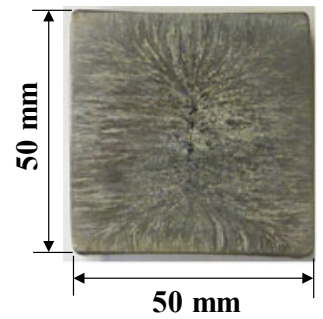

(b)

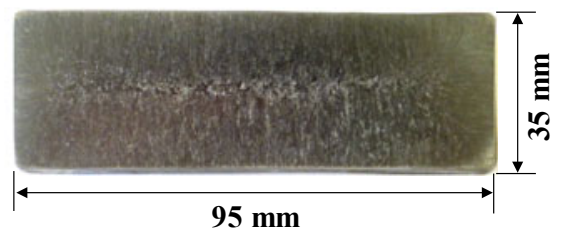

Fig. 2.8 Cross sections of a 16-7-6 and b Cr15NC11.20 cast ingots 


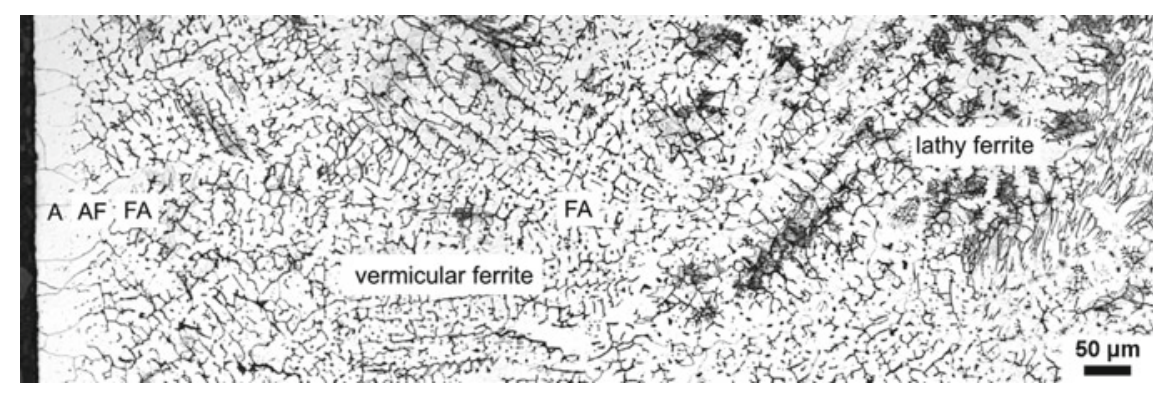

Fig. 2.9 Varied solidification mode from the outer surface (left) towards the core (right) of the Cr19NC14.16 ingot: $\mathrm{A} \rightarrow \mathrm{AF} \rightarrow \mathrm{FA} . \mathrm{V}_{2}$ A reagent was used as etchant [19]

All the cast ingots exhibit pronounced dendritic microstructures and heterogeneous phase distribution as exemplified by Cr19NC14.16 in Fig. 2.9. At the outer layer of the ingot, due to the enormous undercooling of the melt generated by its direct contact with the cold mold, austenite forms at first with segregation of ferrite stabilizer $\mathrm{Cr}$ in the melt. The solidification heat release in the front reduces the undercooling of the melt. Along with the enriched $\mathrm{Cr}$ content in the melt, the solidification mode changes from primary Austenite (A) to Austenite-Ferrite (AF). Therefore, from the outer layer towards the center, the solidification mode varies in sequence: primary Austenite (A) $\rightarrow$ Austenite-Ferrite (AF) $\rightarrow$ Ferrite-Austenite (FA). The solidification modes were estimated according to substitutional distributions obtained from energy-dispersive X-ray spectroscopy (EDS) analysis.

The microstructures and corresponding phase fractions of the cast steels are revealed in Figs. 2.10 and 2.11. With increasing $\mathrm{C}$ contents, the microstructure of Cr15NC10.X steels at RT varies in sequence: $\gamma+\alpha^{\prime}+\delta \rightarrow \gamma+\alpha^{\prime} \rightarrow \gamma$. For the Cr19NC15.X steel, on the other hand, the sequence changes with increasing $\mathrm{C}$ contents from $\gamma+\delta$ to $\gamma$.

\subsubsection{Austenite $\leftrightarrow \alpha^{\prime}$-Martensite Transformation Behavior}

As illustrated in Fig. 2.12, the $M_{s}, A_{s}$, and $A_{f}$ temperatures of Cr15NC10.X steels decrease all linearly at higher interstitial contents [39]. Figure 2.13 shows the $f_{\alpha^{\prime}}^{Q}$ of Cr15NC10.X steels at various temperatures. With decreasing temperature, $f_{\alpha^{\prime}}^{Q}$ in all steels initially increases and then decreases below a certain temperature. The transition temperatures, ranging from -81 to $-141^{\circ} \mathrm{C}$ as marked by crosses, are in the vicinity of $T_{\mathrm{N}}$ (between -132 and $-128{ }^{\circ} \mathrm{C}$ ). This phenomenon has been reported in [41]. At $T_{\mathrm{N}}$, the magnetic state of austenite changes from paramagnetic to antiferromagnetic. This is accompanied by changes in the physical properties, such as a reduction in the elastic modulus, thermal conductivity and thermal expansion coefficient [42]. The associated magnetic ordering also reduces the entropy of austenite [43], so that the free energy of austenite increases at a smaller rate with decreasing 

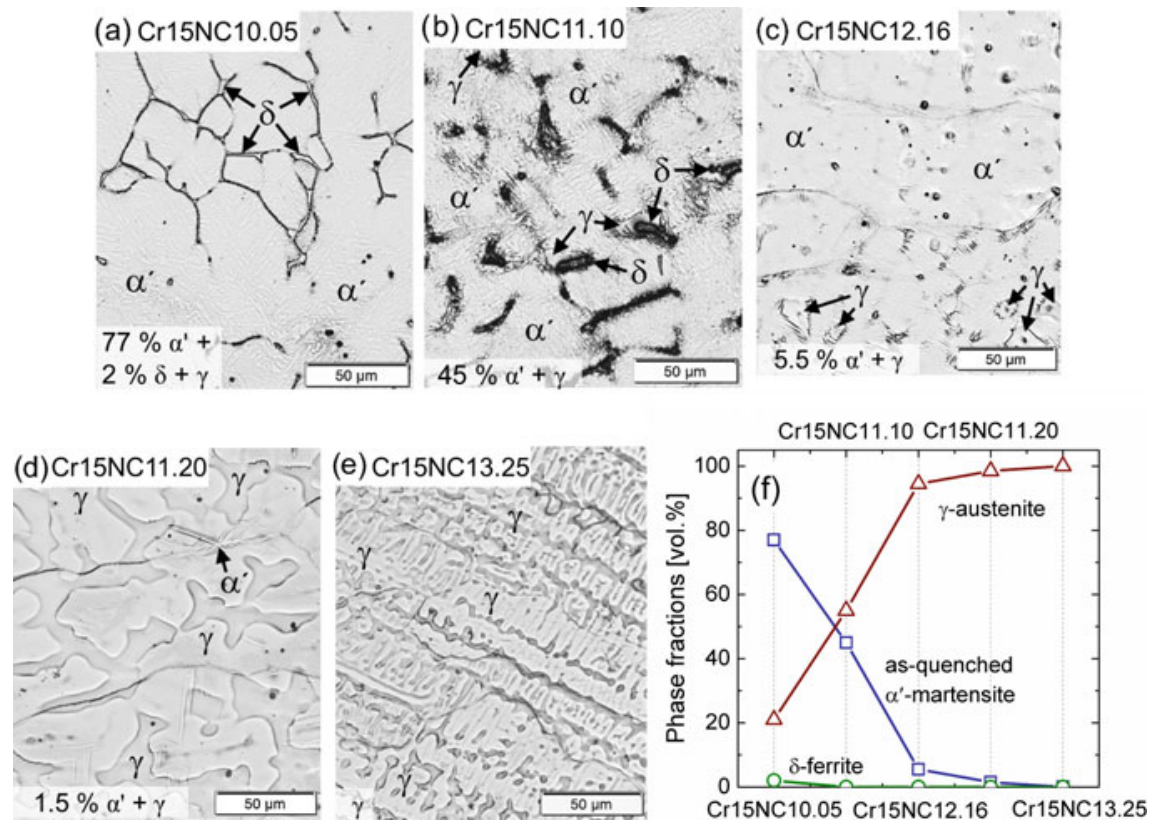

Fig. 2.10 a-e Microstructures and $\mathbf{f}$ phase fractions of cast Cr15NC10.X steels. Etchant: $\mathrm{HNO}_{3}$ Adapted from [19]

temperature. As a consequence, the absolute difference between the free energy of austenite and $\alpha^{\prime}$-martensite is reduced. In other words, the chemical driving force for $\alpha^{\prime}$-martensitic transformation is lowered. Hence, $f_{\alpha^{\prime}}^{Q}$ stops increasing even in the presence of a high austenite fraction (e.g. Cr15NC11.20). In addition, the decayed kinetics of isothermal $\alpha^{\prime}$-martensitic transformation [44] leads to a decrease in $f_{\alpha^{\prime}}^{Q}$ below $T_{\mathrm{N}}$. Therefore, the reduction in $f_{\alpha^{\prime}}$ after passing through a peak at cryogenic temperatures can be attributed to the reduction in both the chemical driving force and the kinetics of transformation at temperatures below $T_{\mathrm{N}}$.

For the Cr19NC15.X series, even after a cryogenic treatment in liquid nitrogen, it was not possible to introduce as-quenched $\alpha^{\prime}$-martensite in the solution annealed cast steels.

\subsubsection{Mechanical Properties of Cr15NC10.X Steel Series}

The stress-strain curves and associated mechanical properties are exemplified by those tested at RT and $200{ }^{\circ} \mathrm{C}$ as shown in Fig. 2.14. In Fig. 2.15, the mechanical properties and $f_{\alpha^{\prime}}^{\text {ind. }}$ are presented as functions of the tensile test temperature. The $M_{s}$ temperatures of steels are also marked by vertical dash-dotted lines. In most steels, YS improves from RT to $100{ }^{\circ} \mathrm{C}$ due to the precipitation of fine transition carbides 


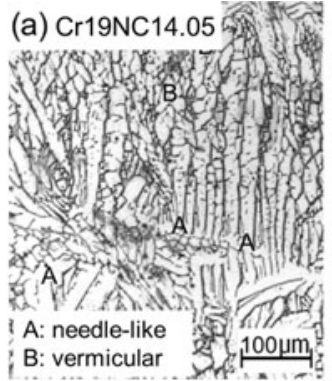

(b) $\operatorname{Cr} 19 \mathrm{NC} 15.10 \div(\mathrm{A})$ (b) Cr19NC15.10 7 .

(c) Cr19NC14.16

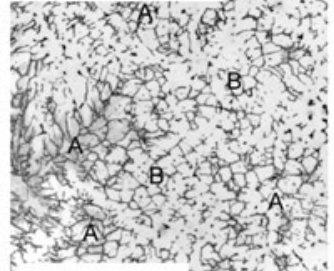

A: lathy

B: vermicular

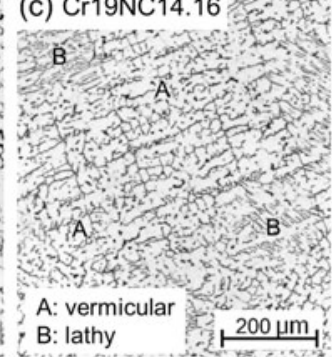

Cr19NC15.10 Cr19NC16.21
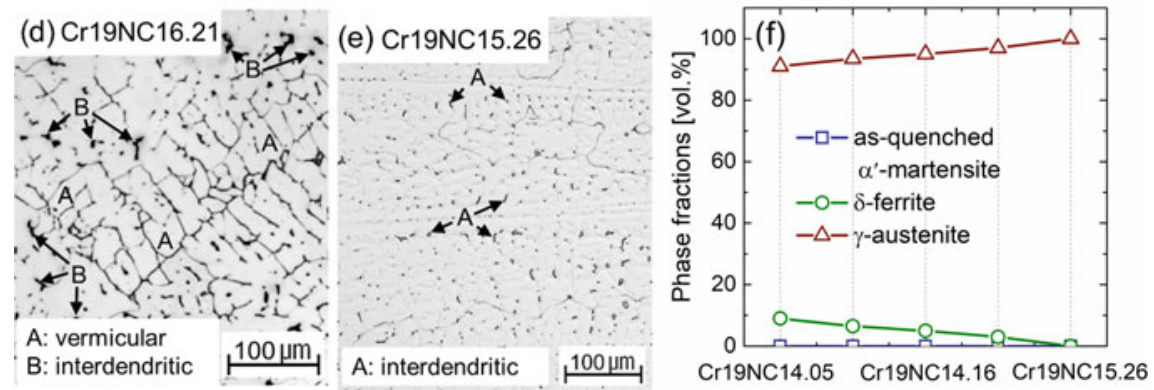

Fig. 2.11 a-e Microstructures and $\mathbf{f}$ phase fractions of cast Cr19NC15.X steels. Etchant: $\mathrm{HNO}_{3}$. Adapted from [19]

Fig. 2.12 $M_{s}, A_{s}, A_{f}$

temperatures of

Cr15NC10.X steels [39]

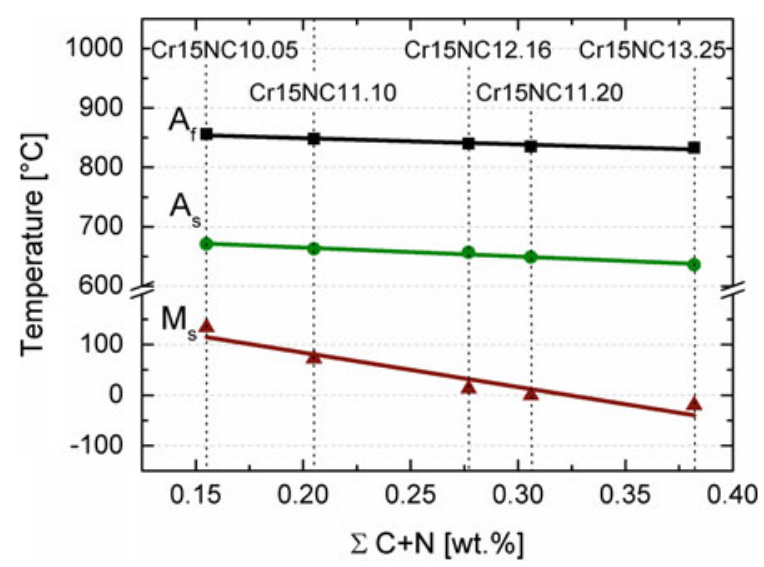

and nitrides in the $\alpha^{\prime}$-martensitic constituent, while TE and UE increase as a result of improved austenite stability against $\alpha^{\prime}$-martensitic transformation. Accordingly, $f_{\alpha^{\prime}}^{\text {ind. }}$ decreases, except for the steels with $0.05-0.16 \mathrm{wt} \% \mathrm{C}$ when temperature increases from $-40{ }^{\circ} \mathrm{C}$ to $\mathrm{RT}$. The latter variation is due to the raised $f_{\alpha^{\prime}}^{Q}$ at $-40{ }^{\circ} \mathrm{C}$ compared 


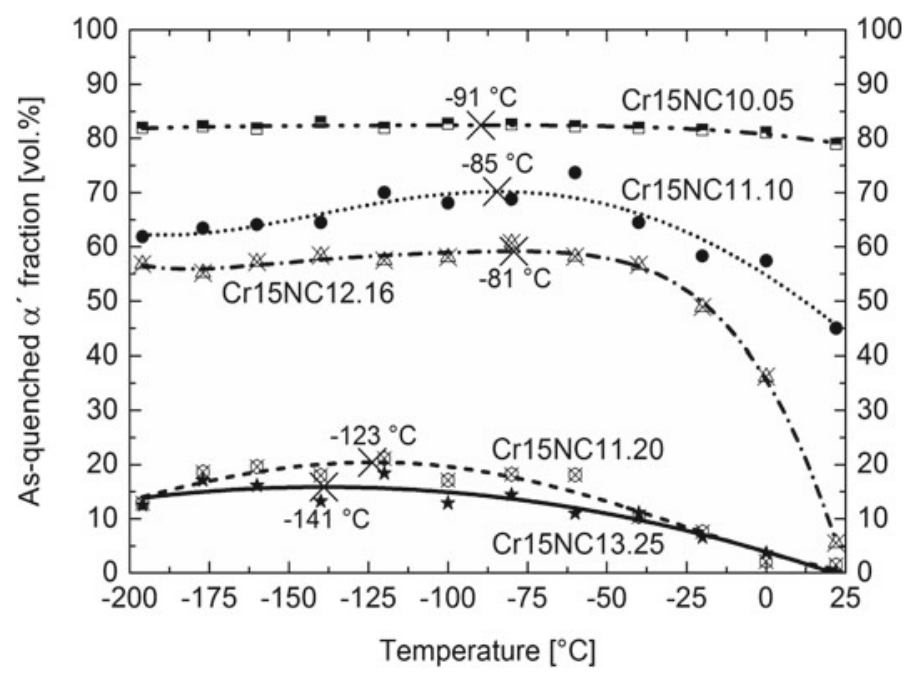

Fig. 2.13 $f_{\alpha^{\prime}}^{Q}$ of Cr15NC10.X steels after holding for $10 \mathrm{~min}$ at various temperatures [39]. The crosses mark the temperatures associated with maximum $f_{\alpha^{\prime}}^{Q}$

(a)

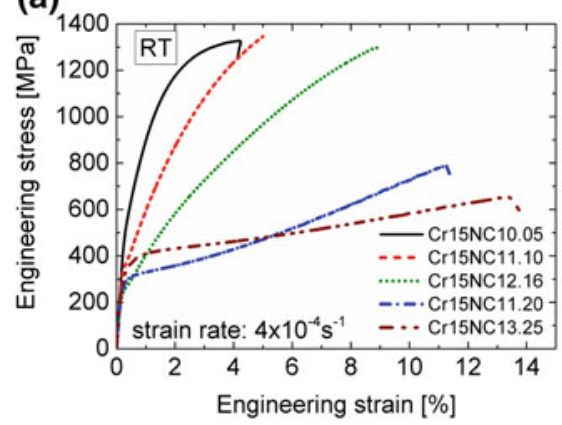

(b)

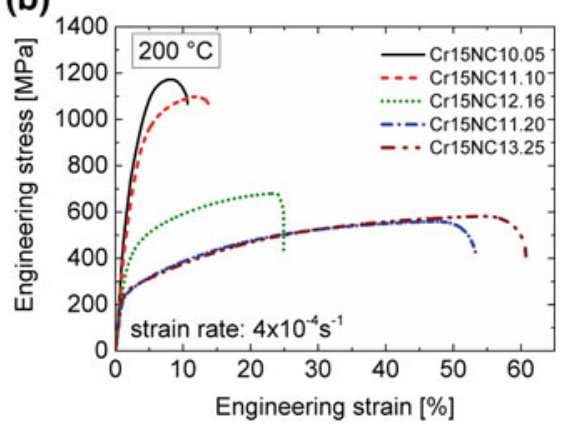

Fig. 2.14 The stress-strain curves of Cr15NC10.X steels at RT (a) and at $200{ }^{\circ} \mathrm{C}$ (b) [39]

to RT. Namely, the lower initial fractions of retained austenite at $-40{ }^{\circ} \mathrm{C}$ resulted in a smaller $f_{\alpha^{\prime}}^{\text {ind. }}$ than that tensile tested at RT.

The high stability of austenite at $200{ }^{\circ} \mathrm{C}$ is primarily a result of a raised SFE. Nevertheless, in alloys containing as-quenched $\alpha^{\prime}$-martensite such as Cr15NC10.05 and $\mathrm{Cr} 15 \mathrm{NC} 11.10$, the thermal stabilization of austenite might have also contributed to its enhanced stability [45]. Although the temperature is too low for the long-range diffusion of $\mathrm{C}$ and $\mathrm{N}$ in the austenite, it is sufficiently high for them to diffuse from the supersaturated $\alpha^{\prime}$-martensite to the $\gamma-\alpha^{\prime}$ phase boundaries. For instance, the diffusion distance of $\mathrm{C}$ in the $\alpha^{\prime}$-martensite is $4-20 \mathrm{~nm}$ at $200{ }^{\circ} \mathrm{C}$ within the timeframe of $20 \mathrm{~min}$ necessary for the temperature equalization of the tensile test specimens 

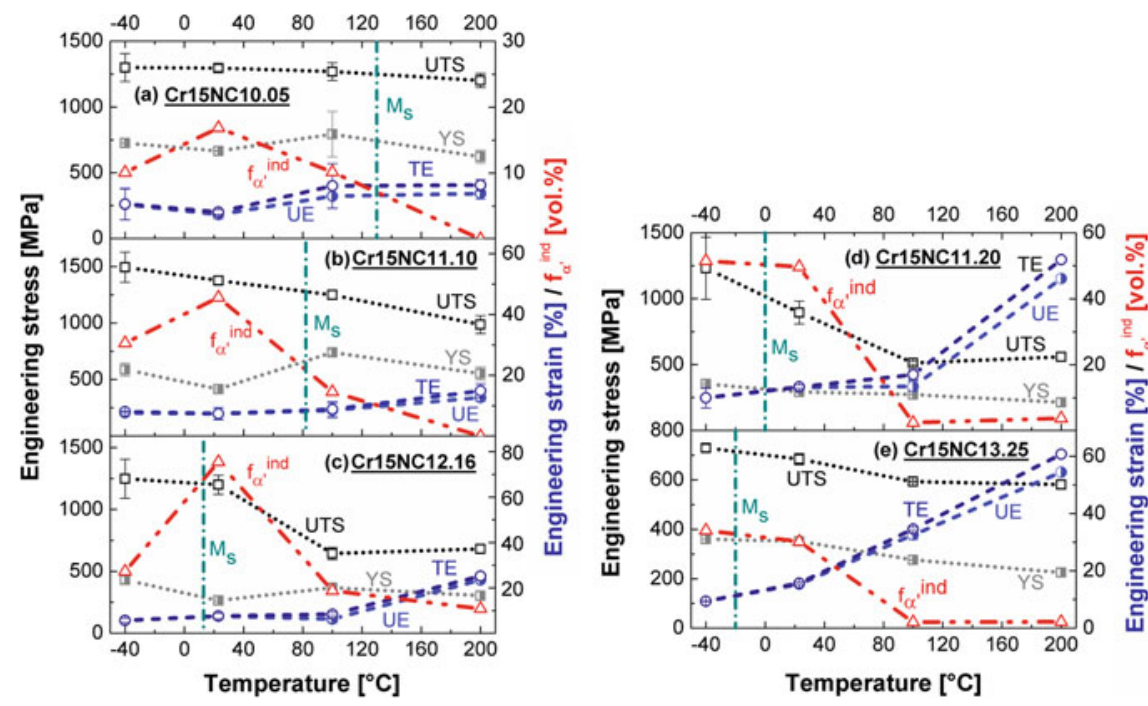

Fig. 2.15 Mechanical properties, $f_{\alpha^{\prime}}^{\text {ind. }}$ and $M_{s}^{\gamma} \rightarrow \alpha^{\prime}$ temperatures of Cr15NC10.X [19]

before tensile loading [39]. The enrichment of $\mathrm{C}$ atoms at phase boundaries reduces the potential nucleation sites for $\alpha^{\prime}$-martensite and hence, improves the resistance of austenite against $\alpha^{\prime}$-martensitic transformation. This effect was confirmed by quenching two solution annealed $\mathrm{Cr} 15 \mathrm{NC} 11.10$ samples in liquid nitrogen. One of them was thermally treated at $200{ }^{\circ} \mathrm{C}$ for $20 \mathrm{~min}$ before quenching in liquid nitrogen. After quenching, the sample held at $200{ }^{\circ} \mathrm{C}$ showed a $f_{\alpha^{\prime}}$ of only $46 \mathrm{vol} \%$ compared to $63 \mathrm{vol} \% \alpha^{\prime}$-martensite formation in the sample without treatment at $200{ }^{\circ} \mathrm{C}$. Due to the local interstitial content change leading to thermal stabilization of austenite, the $M_{d}$ temperatures could not be determined.

\subsubsection{Mechanical Properties of Cr19NC15.X Steel Series}

Figure 2.16 shows the stress-strain curves of the Cr19NC15.X steels deformed at -40 and $200{ }^{\circ} \mathrm{C}$. The $\mathrm{S}$-shape curves at $-40{ }^{\circ} \mathrm{C}$ imply the deformation-induced $\alpha^{\prime}$-martensite formation. In contrast, no noticeable increase in work hardening can be detected at $200{ }^{\circ} \mathrm{C}$. At $-40{ }^{\circ} \mathrm{C}$, YS increases from $372 \mathrm{MPa}$ at $0.05 \mathrm{wt} \% \mathrm{C}$ to $413 \mathrm{MPa}$ at $0.26 \mathrm{wt} \% \mathrm{C}$. This is due to the solid solution strengthening effect of C. The highest UTS of $1326 \mathrm{MPa}$ combined with a TE of $44 \%$ is achieved in the case of the Cr19NC14.16 steel. In stable austenitic steels, an increase in the SFE is expected to decrease the elongation. This behavior can be justified by the dominance of wavy glide mode and the reduced planarity of dislocation glide. Nevertheless, at

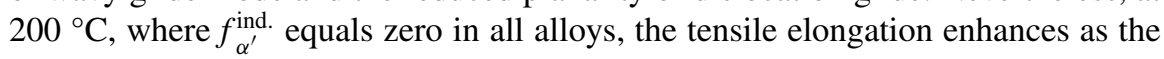
$\mathrm{C}$ concentration and thereby the SFE of austenite increases [46]. Consistent with the 
enhanced elongation, the ECC images of the deformed steels in Figs. 2.17a, c and e reveal a higher density of deformation bands at higher $\mathrm{C}$ contents.

The improved ductility at higher $\mathrm{C}$ contents can be attributed to the increasing segregation of substitutional elements including $\mathrm{Cr}, \mathrm{Mn}$ and $\mathrm{Ni}$. The higher $\mathrm{Ni}_{\text {eq }}$ alters the solidification mode from FA to AF [47]. For $\mathrm{Fe}-\mathrm{Cr}-\mathrm{Ni}$ alloys, the distribution coefficients between the primary $\delta$-ferrite and the melt are $0.95-1.05$ for $\mathrm{Cr}$ and $0.7-0.8$ for $\mathrm{Ni}$ [48]. The distribution coefficients between the primary austenite and the melt, on the other hand, are $0.7-0.8$ for $\mathrm{Cr}$ and 0.95 for $\mathrm{Ni}$ [48]. Due to the much higher $\mathrm{Cr}$ content of the studied steels compared to their $\mathrm{Ni}$ content, the change of solidification mode from FA to AF promotes the substitutional segregation, primarily $\mathrm{Cr}$ segregation, to the interdendritic regions. This was also confirmed by EDS analysis. The associated inhomogeneity of the chemical composition in turn leads
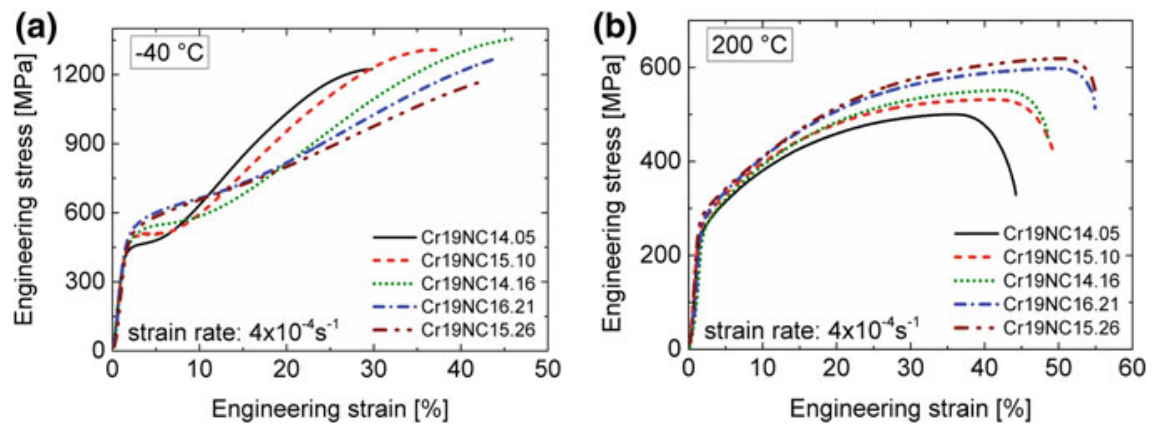

Fig. 2.16 Stress-strain curves of $\mathrm{Cr} 19 \mathrm{NC} 15 . \mathrm{X}$ steels at $-40{ }^{\circ} \mathrm{C}$ (a) and at $200{ }^{\circ} \mathrm{C}(\mathbf{b})$ [19]
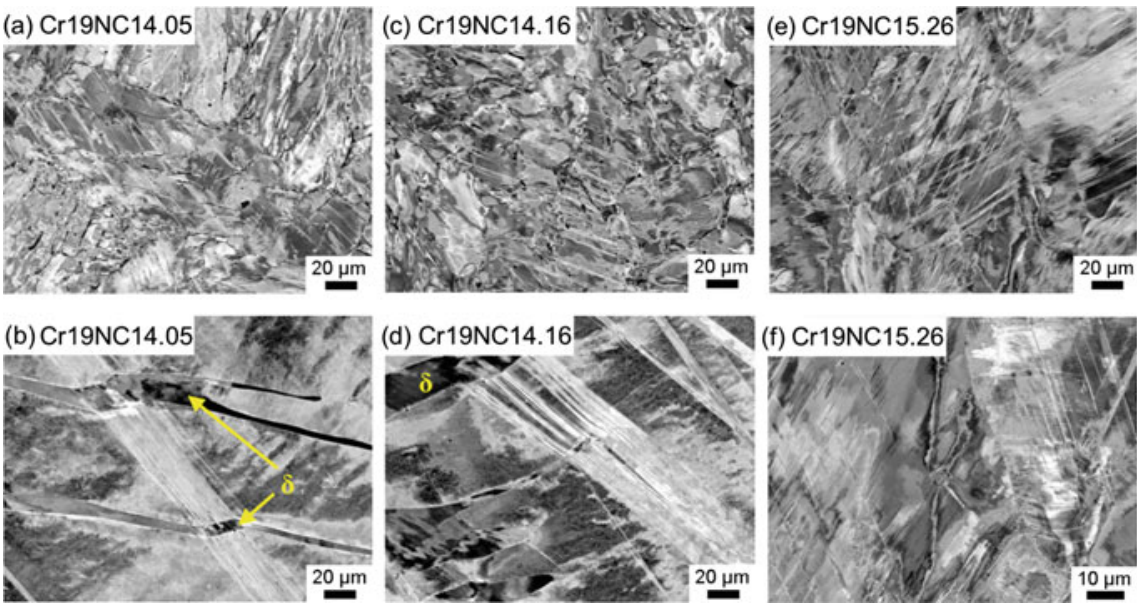

Fig. 2.17 ECC images of indicated steels strained to a, b $42 \%$, c, d $48 \%$, and e, f $55 \%$ at $200{ }^{\circ} \mathrm{C}$. The samples were taken from the uniformly deformed regions in gauge section [19] 
to regions with varying SFE and local variations in the plastic deformation accommodation mechanism. As shown in Fig. 2.17e for the Cr19NC15.26 steel, multiple deformation mechanisms were activated in one austenite grain. The diversification of deformation mode results in the enhanced tensile elongation.

Different interaction behavior was observed between slip bands and $\delta$-ferrite depending on the thickness of $\delta$-ferrite. According to Fig. $2.17 \mathrm{~b}$, it appears that at small thickness, although deformation bands stop at the phase boundaries, the deformation propagate to the adjacent austenite region and activate further slip bands. At high thickness (Fig. 2.17d), the strain is accommodated by the thick $\delta$-ferrite and no further slip bands are generated in the next austenite region.

The temperature dependences of mechanical properties in Cr19NC15.X series as well as $f_{\alpha^{\prime}}^{\text {ind. }}$ and $M_{d}$ temperatures are summarized in Fig. 2.18. At higher temperatures, YS decreases nearly linearly, while UTS decreases with a stronger dependence on $f_{\alpha^{\prime}}^{\text {ind. }} . M_{d}$ decreases from $106^{\circ} \mathrm{C}$ at $0.05 \mathrm{wt} \% \mathrm{C}$ to $46^{\circ} \mathrm{C}$ at $0.26 \mathrm{wt} \% \mathrm{C}$.

The maximum TE is achieved at temperatures where pronounced twinning occurs. This is exemplified in Fig. 2.19 by the $\mathrm{Cr} 19 \mathrm{NC} 14.16$ steel tested at $60{ }^{\circ} \mathrm{C}$ and the Cr19NC15.26 steel tested at $80{ }^{\circ} \mathrm{C}$. The elongation peaks of $\mathrm{Cr} 19 \mathrm{NC} 16.21$ and Cr19NC15.26 steels are clearly broadened, especially Cr19NC15.26 with the maximum TE of approximately $65 \%$ at $40-80{ }^{\circ} \mathrm{C}$. This is related to the coexistence of regions with various austenite stabilities as a result of pronounced substitutional segregation under AF solidification mode. Local variations in the stability/SFE is in turn associated with local variations in the temperature dependence of ductility. Accordingly, the overall temperature dependence of ductility is the weighted average of the different regions. This can in turn result in a broadened elongation peak. In
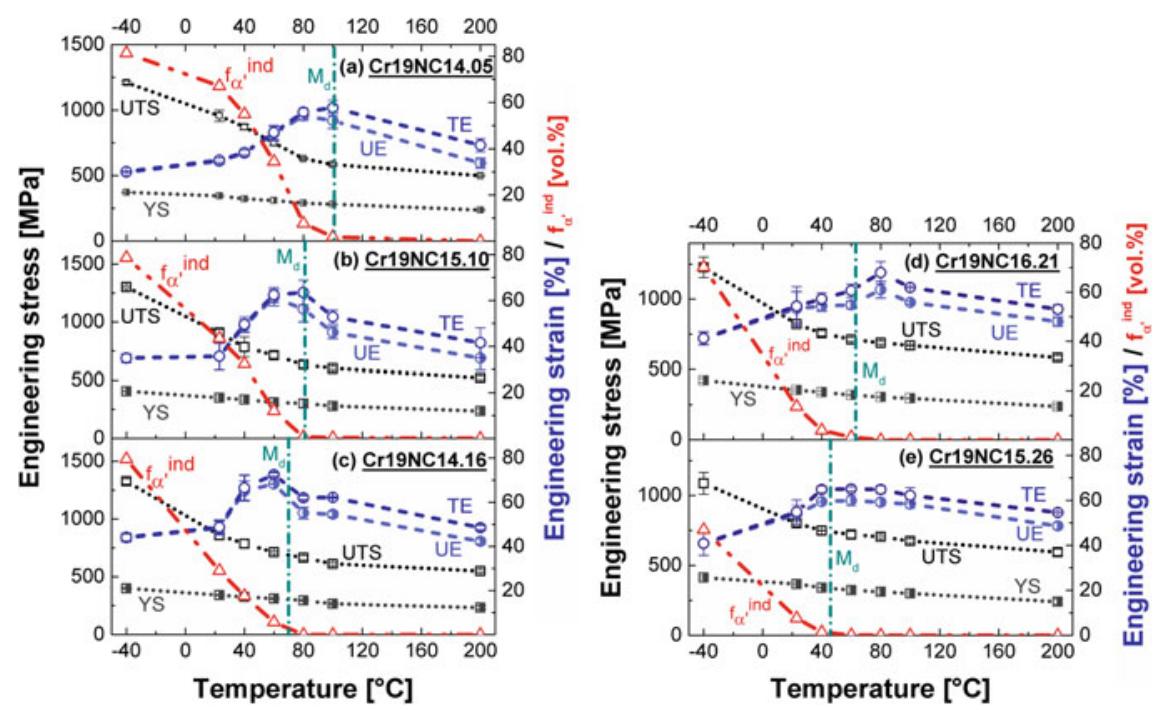

Fig. 2.18 Mechanical properties, $f_{\alpha^{\prime}}^{\text {ind. }}$ and $M_{d}^{\gamma \rightarrow(\mathrm{SF}, \varepsilon) \rightarrow \alpha^{\prime}}$ temperatures in Cr19NC15.X [19] 

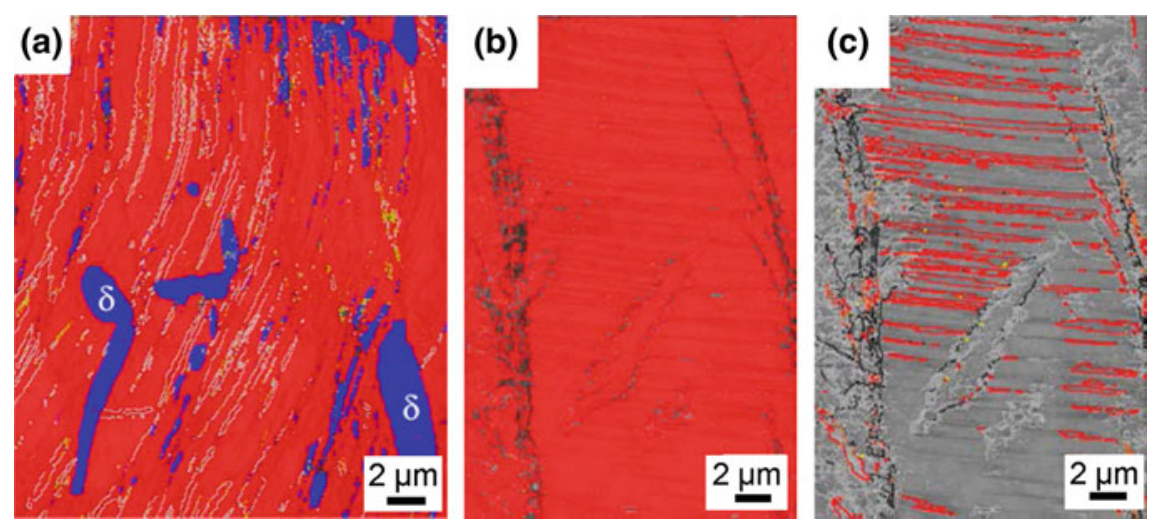

Fig. 2.19 Phase maps of a $\mathrm{Cr} 19 \mathrm{NC} 14.16$ steel tested at $60{ }^{\circ} \mathrm{C}$ [28] and b $\mathrm{Cr} 19 \mathrm{NC} 15.26$ tested at $80{ }^{\circ} \mathrm{C}$ [19]; c Map of $\Sigma 3$ twin boundaries (red lines) superimposed with image quality map corresponding to the phase map in (b) [19]. In (a) and (b): red: austenite, blue: $\delta$-ferrite or $\alpha^{\prime}$ martensite, yellow: $\varepsilon$-martensite, white: twin boundaries, grey: not indexed

addition, pronounced substitutional segregation in a cast $\mathrm{Fe}-14.3 \mathrm{Cr}-5.5 \mathrm{Mn}-5.5 \mathrm{Ni}-$ $0.5 \mathrm{Si}-0.37 \mathrm{~N}-0.02 \mathrm{C}$ steel was found to result in an enhanced ductility at cryogenic

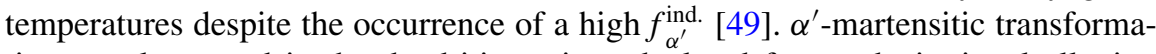
tion mostly started in the dendritic regions depleted from substitutional alloying elements. Nevertheless, the formation of fresh $\alpha^{\prime}$-martensite at temperatures below $M_{d}$ was compensated by the enhanced glide planarity and ductility of the surrounding interdendritic regions, leading to an enhancement of TE.

\subsubsection{Conclusions for the $2^{\text {nd }}$ Generation Steels}

The $2^{\text {nd }}$ generation steels consist of interstitially-alloyed cast stainless steels Cr15NC10.X and Cr19NC15.X with C concentrations ranging from 0.05 to $0.25 \mathrm{wt} \%$. The following conclusions were drawn:

1. Upon quenching, $f_{\alpha^{\prime}}^{Q}$ stops increasing in the vicinity of $T_{\mathrm{N}}$ before the exhaustion of austenite. This is due to the decreased chemical driving force for transformation and the reduced kinetics of transformation at temperatures below $T_{\mathrm{N}}$.

2. The phase constituents, SFE, $M_{s}$ and $M_{d}$ temperatures, as well as mechanical properties at RT of Cr15NC10.X and Cr19NC15.X steels are summarized in Tables 2.6 and 2.7 .

3. At $200{ }^{\circ} \mathrm{C}$, strain-induced $\alpha^{\prime}$-martensitic transformation was fully suppressed in Cr19NC15.X steels. Both strength and ductility enhance at increasing C concentrations. The improved ductility was attributed to more pronounced substitutional segregation generated during primary austenitic solidification. 
Table 2.6 Summarized properties of Cr15NC10.X steels

\begin{tabular}{l|l|l|l|l|l}
\hline $\mathrm{X}$ & 0.05 & 0.10 & 0.15 & 0.2 & 0.25 \\
\hline Cast microstructure & $\gamma+\alpha^{\prime}+\delta$ & $\gamma+\alpha^{\prime}$ & $\gamma+\alpha^{\prime}$ & $\gamma+\alpha^{\prime}$ & $\gamma$ \\
\hline$f_{\alpha^{\prime}}$ of cast $(\mathrm{vol} \%)$ & 77 & 45 & 5.5 & 1.5 & 0 \\
\hline SFE $\left(\mathrm{mJm}^{-2}\right)$ & 12 & 14 & 18 & 20 & 24 \\
\hline$M_{s}\left({ }^{\circ} \mathrm{C}\right)$ & 135 & 82 & 13 & 0 & -20 \\
\hline YS at RT $(\mathrm{MPa})$ & 665 & 415 & 263 & 293 & 352 \\
\hline UTS at RT $(\mathrm{MPa})$ & 1296 & 1377 & 1199 & 895 & 684 \\
\hline TE at RT $(\%)$ & 4 & 7 & 8 & 13 & 15 \\
\hline UTS $\times$ TE $(\mathrm{GPa} \%)$ & 5.2 & 9.6 & 9.6 & 11.6 & 10.3 \\
\hline
\end{tabular}

Table 2.7 Summarized properties of Cr19NC15.X steels

\begin{tabular}{l|l|l|l|l|l}
\hline $\mathrm{X}$ & 0.05 & 0.10 & 0.15 & 0.2 & 0.25 \\
\hline Cast microstructure & $\gamma+\delta$ & $\gamma+\delta$ & $\gamma+\delta$ & $\gamma+\delta$ & $\gamma$ \\
\hline$\delta$ fraction of cast $(\mathrm{vol} \%)$ & 9 & 6.5 & 5 & 3 & 0 \\
\hline $\mathrm{SFE}\left(\mathrm{mJm}^{-2}\right)$ & 14 & 17 & 21 & 26 & 30 \\
\hline$M_{d}\left({ }^{\circ} \mathrm{C}\right)$ & 100 & 81 & 70 & 63 & 46 \\
\hline YS at RT $(\mathrm{MPa})$ & 345 & 351 & 342 & 355 & 368 \\
\hline UTS at RT $(\mathrm{MPa})$ & 956 & 903 & 861 & 822 & 801 \\
\hline TE at RT $(\%)$ & 35 & 36 & 48 & 54 & 55 \\
\hline UTS $\times$ TE $(\mathrm{GPa} \%)$ & 33.5 & 32.5 & 41.3 & 44.4 & 44.1 \\
\hline
\end{tabular}

4. The prominent substitutional segregation at 0.20 and $0.26 \mathrm{wt} \% \mathrm{C}$ in $\mathrm{Cr} 19 \mathrm{NC} 15 . \mathrm{X}$ also leads to the broadening of the elongation peak in the diagrams exhibiting the temperature dependent average mechanical properties.

\subsection{Q\&P Processing of Austenitic CrMnNi-C-N Cast Steels}

The $2^{\text {nd }}$ generation steels exhibit either a high YS with a low TE due to a large $f_{\alpha^{\prime}}^{Q}$ (e.g. an average YS of $650 \mathrm{MPa}$ and an average TE of $9 \%$ for the $\mathrm{Cr} 15 \mathrm{NC} 11.10$ steel) or a low YS with an excellent TE (e.g. an average YS of $325 \mathrm{MPa}$ and an average TE of $60 \%$ for the Cr19NC14.16 steel). Clearly, a high YS demands the presence of tempered $\alpha^{\prime}$-martensite. Therefore, Q\&P processing was applied for the $3^{\text {rd }}$ generation steels to obtain austenitic-martensitic microstructures to ensure an adequate combination of strength and ductility. Ever since its proposal in 2003 [50], Q\&P processing has been widely applied to low-alloy and stainless steels [5153]. It involves partial transformation of austenite into $\alpha^{\prime}$-martensite, followed by heating to a higher temperature, where the diffusion of the supersaturated $\mathrm{C}$ and $\mathrm{N}$ 
from fresh $\alpha^{\prime}$-martensite into austenite is enabled [54]. The final microstructure consists of C-enriched austenite and C-depleted $\alpha^{\prime}$-martensite. Two steels with medium C contents, $\mathrm{Cr} 15 \mathrm{NC} 12.16$ and $\mathrm{Cr} 19 \mathrm{NC} 14.16$, were selected for the application of $\mathrm{Q} \& \mathrm{P}$ processing. The $3^{\text {rd }}$ generation steels are denoted as AMC based on their final microstructures containing Austenite and tempered $\alpha^{\prime}$-Martensite with embedded Carbides.

\subsubsection{Constitution and Special Methods}

The Q\&P processing routine for the Cr15NC12.16 steel with a composition given in Table 2.4 is illustrated in Fig. 2.20a. It involves solution annealing at $1150{ }^{\circ} \mathrm{C}$ followed by quenching to RT and subsequently to a subzero temperature above $T_{\mathrm{N}}$ to create a sufficiently high $f_{\alpha^{\prime}}^{Q}$. Based on the $f_{\alpha^{\prime}}^{Q}$ values presented in Fig. $2.13,-130{ }^{\circ} \mathrm{C}$ was selected for subzero quenching. The resulting microstructure consisted of $58 \mathrm{vol} \% \alpha^{\prime}$-martensite and $42 \mathrm{vol} \%$ austenite. It was then partitioned at $450{ }^{\circ} \mathrm{C}$ for $3 \mathrm{~min}$. In contrast, no $\alpha^{\prime}$-martensite could be obtained in $\mathrm{Cr} 19 \mathrm{NC} 14.16$ steel (composition shown in Table 2.5) even when quenched in liquid nitrogen. Hence, $\alpha^{\prime}$-martensite was introduced by deformation below $M_{d}$ subsequent to quenching from $1150{ }^{\circ} \mathrm{C}$ (Fig. 2.20b). The pre-strained specimens were then partitioned at $450{ }^{\circ} \mathrm{C}$ for $3 \mathrm{~min}$. This process is referred to as Quenching-Deformation-Partitioning (QDP) processing. As shown in Fig. 2.18c, the steel Cr19NC14.16 possesses an $M_{d}$ temperature of $70{ }^{\circ} \mathrm{C}$. At lower testing temperatures, a smaller strain is required to generate strain-induced $\alpha^{\prime}$-martensite. Hence, pre-straining was performed at

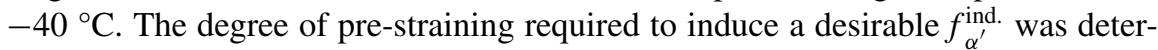
mined by a tensile test at $-40{ }^{\circ} \mathrm{C}$ with in situ magnetic measurement to estimate the $f_{\alpha^{\prime}}^{\text {ind. }}$ evolution according to the procedure described in [55]. In addition, interrupted tensile testes at engineering strains of 5, 15 and $25 \%$ were performed to quantify $f_{\alpha^{\prime}}^{\text {ind. }}$ with ex situ magnetic measurements. The $\mathrm{C}$ and $\mathrm{N}$ enrichment in the austenite during

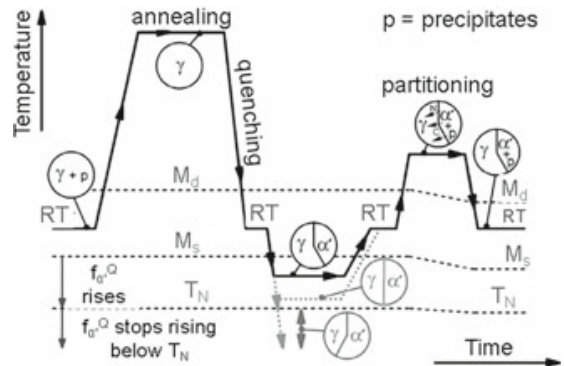

(a) $\mathrm{Cr} 15 \mathrm{NC12.16}$

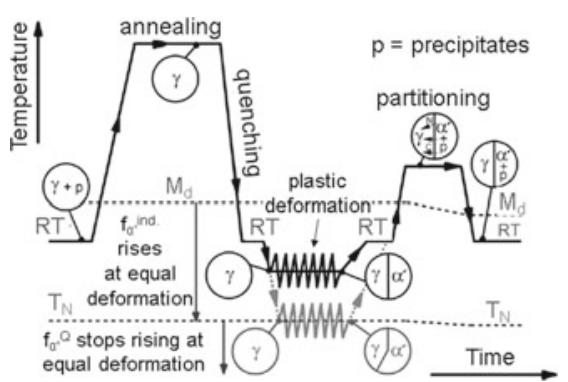

(b) Cr19NC14.16

Fig. 2.20 Schematic illustrations of a Q\&P processing for Cr15NC12.16 steel [27] and b QDP processing for Cr19NC14.16 steel [28] 
partitioning was studied based on the variations in the austenite lattice parameter. This was done by $\mathrm{X}$-ray diffraction (XRD) measurements using $\mathrm{Cu} \mathrm{K} \alpha$ radiation in a Seifert-FPM RD7 diffractometer.

\subsubsection{Q\&P Processing of Cr15NC12.16 Steel}

The microstructure of $\mathrm{Cr} 15 \mathrm{NC} 12.16$ steel quenched to $-130{ }^{\circ} \mathrm{C}$ is demonstrated in Fig. 2.21a. Due to the low austenite stability prior to partitioning, $\alpha^{\prime}$-martensitic transformation occurs during specimen preparation for metallography (preparationinduced $\alpha^{\prime}$-martensite), leading to a $f_{\alpha^{\prime}}^{Q}$ of over 58 vol\% based on an optical microscopy estimation. The remaining untransformed austenite in the micrograph represents the chemically-stabilized interdendritic regions. Based on the EDS analysis of the region marked in Fig. 2.21a as shown in Figs. 2.21b-d, elements including $\mathrm{Cr}, \mathrm{Mn}$ and $\mathrm{Ni}$ are enriched in the austenitic regions. The segregation is most pronounced for $\mathrm{Cr}$ and least for $\mathrm{Ni}$.

Based on the diffusion equation proposed by Ågren [56], the diffusion distance of $\mathrm{C}$ in austenite upon holding at $450{ }^{\circ} \mathrm{C}$ for $3 \mathrm{~min}$ is $693 \mathrm{~nm}$. As $\mathrm{N}$ atoms have a higher diffusion coefficient at $450{ }^{\circ} \mathrm{C}$ than $\mathrm{C}$ atoms, i.e. $5.21 \times 10^{-11} \mathrm{~cm}^{2} \mathrm{~s}^{-1}$ versus $1.46 \times 10^{-11} \mathrm{~cm}^{2} \mathrm{~s}^{-1}$ [57], it is assumed, that the stabilization of austenite could be more significant by N. Substitutional elements are assumed to be immobile in both phases during the applied partitioning conditions [58]. During partitioning, $\mathrm{M}_{3} \mathrm{C}$ carbides formed in $\alpha^{\prime}$-martensite, indicating a reduction in the interstitial content available for the partitioning process. Figure 2.22a shows the SAED pattern of an $\mathrm{M}_{3}$ C-type carbide in a martensitic matrix. Figure $2.22 \mathrm{~b}$ shows a high resolution TEM micrograph of another $\mathrm{M}_{3} \mathrm{C}$-type carbide with a size of approximately $20 \mathrm{~nm}$.

As a result of the enriched interstitial content, austenite peak profiles determined by XRD shift towards lower angles after partitioning. This is exemplified by the $(311)_{\gamma}$ peak in Fig. 2.23. The asymmetric peak profiles could be related to the nonuniform interstitial enrichment of austenite arising from differences in the size and distribution of austenitic regions. An increase in the solute $\mathrm{C}$ content by 1 at. $\%$ was
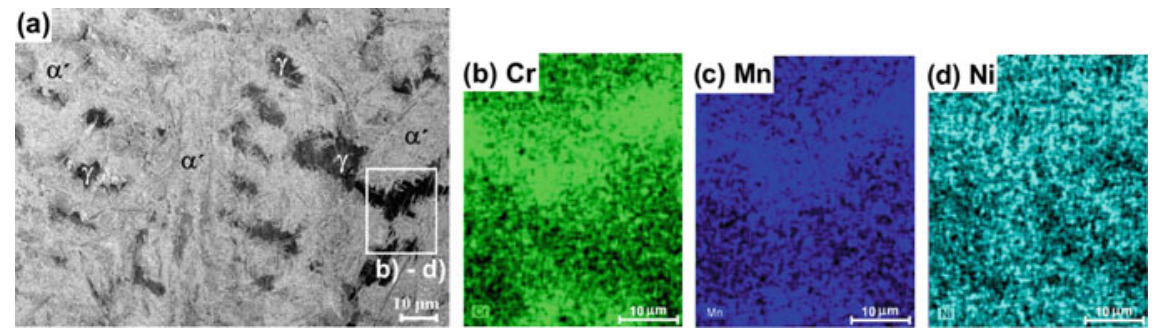

Fig. 2.21 a Optical micrograph of $\mathrm{Cr} 15 \mathrm{NC} 12.16$ steel quenched to $-130{ }^{\circ} \mathrm{C}$; $\mathbf{b}-\mathbf{d}$ Distribution of substitutional alloying elements $\mathrm{Cr}, \mathrm{Mn}$ and $\mathrm{Ni}$ in the region demarcated in (a) [27] 
reported to expand the austenite lattice parameter by $0.00045 \mathrm{~nm}$ [59]. Accordingly, assuming a similar austenite lattice dilatation effect for $\mathrm{N}$, the peak shift in Fig. 2.23 implies an increase in the interstitials content of austenite by $0.1 \mathrm{wt} \%$. In other words, the average interstitial content of austenite increased from 0.28 to $0.38 \mathrm{wt} \%$ after partitioning.

The stress-strain curves of the solution annealed steel are demonstrated in Fig. 2.24a. After Q\&P processing, both UTS and TE were greatly improved (Fig. 2.24b). Because of the high tempered $f_{\alpha^{\prime}}$ and the dispersed fine $\mathrm{M}_{3} \mathrm{C}$ carbides, a YS of $1050 \mathrm{MPa}$ and a UTS of $1550 \mathrm{MPa}$ were achieved at RT. Furthermore, the coexistence of tempered $\alpha^{\prime}$-martensite with $\mathrm{C}$-stabilized austenite resulted in a TE of $22 \%$ (Fig. 2.24c). The phase fractions of the tested Q\&P specimens are shown in

(a)

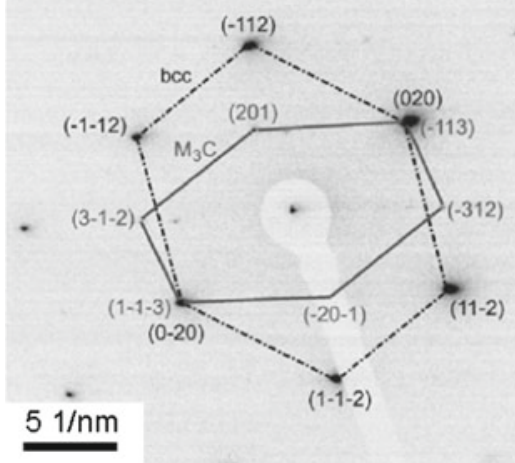

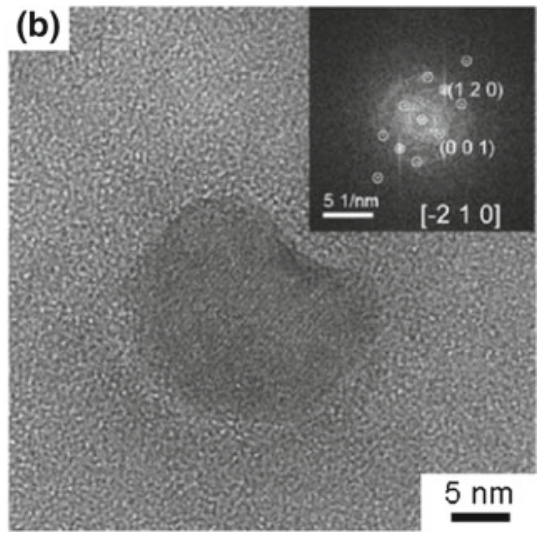

Fig. 2.22 a A SAED pattern of an $\mathrm{M}_{3} \mathrm{C}$-type carbide embedded in tempered $\alpha^{\prime}$-martensite. The zone axes are [201 $]_{\alpha^{\prime}}$ and [17-2 $]_{\mathrm{M} 3 \mathrm{C}}$, respectively; b High resolution TEM image of an $\mathrm{M}_{3} \mathrm{C}$-type carbide and the corresponding FFT image with a $[-210]_{\mathrm{M} 3 \mathrm{C}}$ zone axis for the carbide [27]

Fig. 2.23 XRD $(311)_{\gamma}$ peak profiles of $\mathrm{Cr} 15 \mathrm{NC} 12.16$ in the as-quenched condition $(Q)$ and after partitioning (Q\&P) [27]

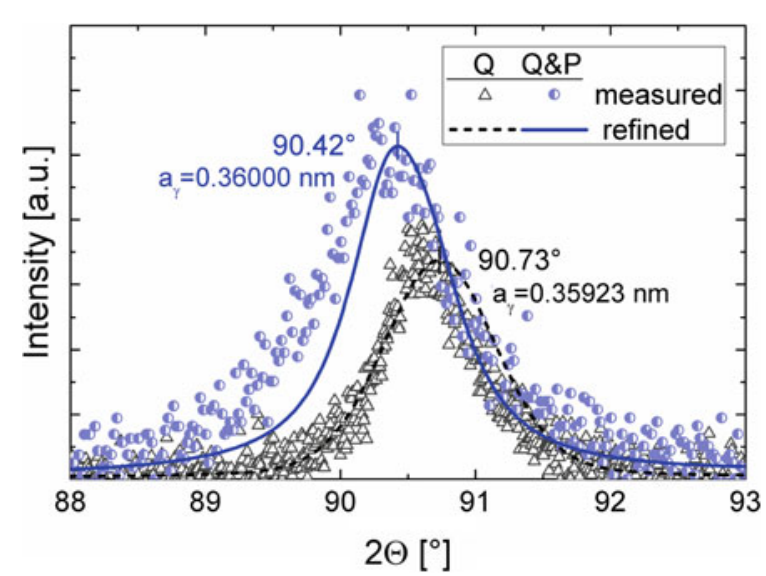


(a)

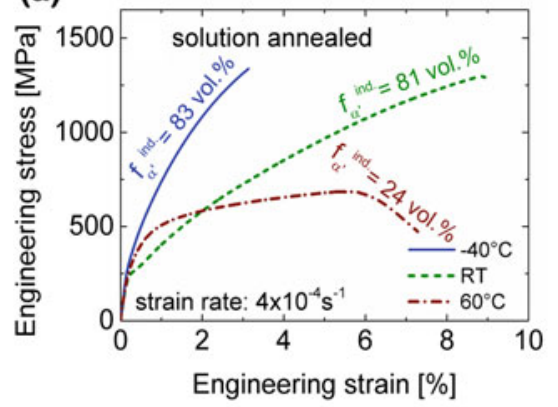

(c)

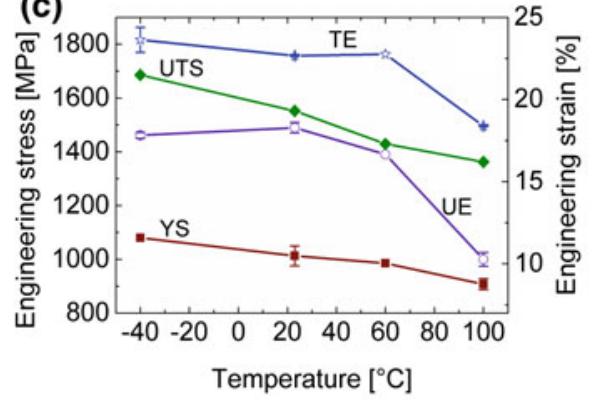

(b)

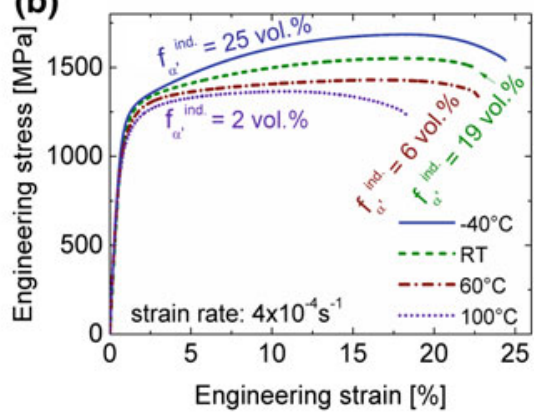

(d)

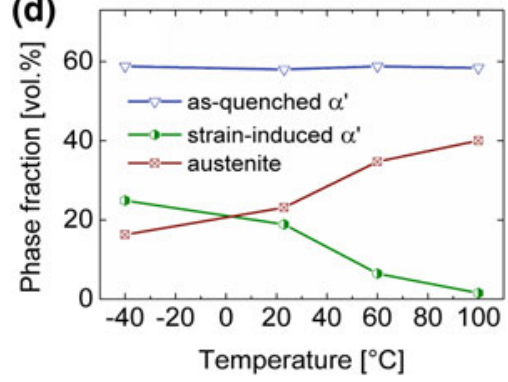

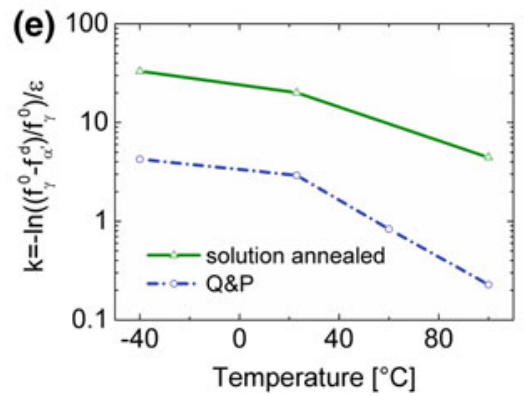

Fig. 2.24 The stress-strain curves of the $\mathrm{Cr} 15 \mathrm{NC} 12.16$ steel in the solution annealed condition (a), and after quenching to $-130{ }^{\circ} \mathrm{C}$ and partitioning at $450{ }^{\circ} \mathrm{C}(\mathbf{b})$; $\mathbf{c}$ average mechanical properties and $\mathbf{d}$ phase fraction evolution of AMC $\mathrm{Cr} 15 \mathrm{NC} 12.16$; e mechanical stability of austenite in the solution annealed and Q\&P conditions [27]

Fig. 2.24d. The formation of strain-induced $\alpha^{\prime}$-martensite inside the austenite deformation bands and at their intersections reduces the mean free path of dislocations (Fig. 2.25a) and hence, improves the strength as well. This justifies the increase in the strain hardening rate at lower temperatures. Within the slip bands in the austenite deformed at $60{ }^{\circ} \mathrm{C}$ (Fig. 2.25b), less $\alpha^{\prime}$-martensite was formed compared to that

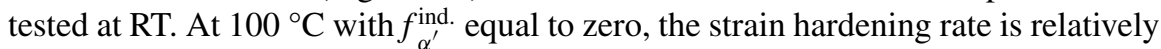
low. 

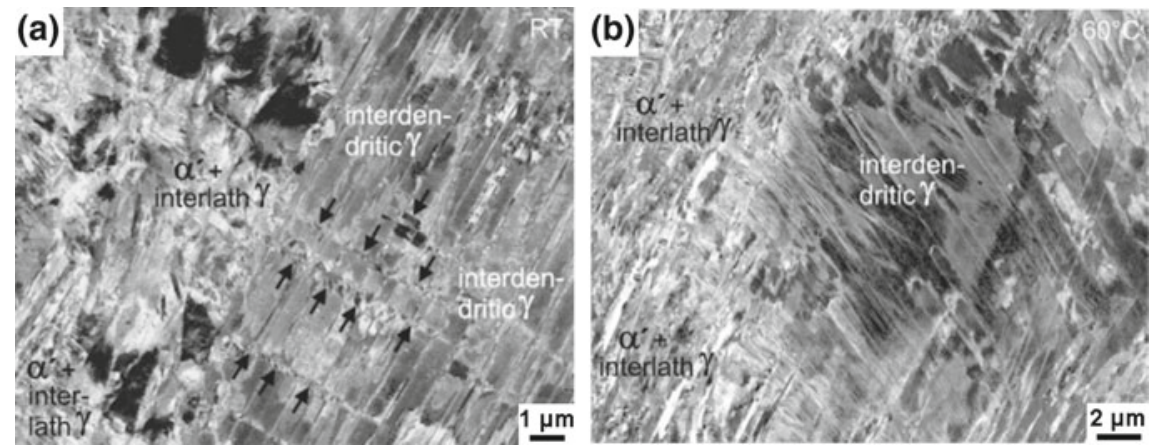

Fig. 2.25 ECC images of AMC Cr15NC12.16 steel tensile tested at RT (a) and $60{ }^{\circ} \mathrm{C}$ (b) [27]. The arrows mark strain-induced $\alpha^{\prime}$-martensite platelets in the deformation bands

The average mechanical stability of austenite was quantified using the following equation proposed by Sugimoto et al. [60]:

$$
k=-\ln \left(\left(f_{\gamma}^{\circ}-f_{\alpha^{\prime}}^{\text {ind. }}\right) / f_{\gamma}^{\circ}\right) / \varepsilon
$$

where, $f_{\gamma}^{\circ}$ is the initial austenite fraction, $\varepsilon$ is the applied true strain, and $k$ is a parameter that is inversely proportional to the mechanical stability of austenite. $k$ calculated using global strain is shown in Fig. 2.24e. The enriched interstitial contents after partitioning indeed improved the austenite stability as confirmed by a much smaller $k$ in the $\mathrm{Q} \& \mathrm{P}$ condition. The mechanical stability at $-40{ }^{\circ} \mathrm{C}$ in partitioned condition nearly equals that of the solution annealed steel at $100{ }^{\circ} \mathrm{C}$.

Similar to [49], TE of the AMC Cr15NC12.16 steel increases even at tempera-

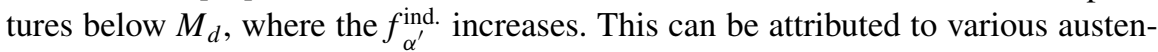
ite stabilities in the dendritic and interdendritic regions. Apart from the elemental redistribution between liquid and solid phases during solidification, Q\&P Processing increases the chemical inhomogeneity and the inequality of the austenite stability in different regions. As the $\alpha^{\prime}$-martensitic transformation upon quenching leads to the fragmentation of austenite, the quenched microstructure consists of martensitic laths and austenitic regions with various sizes. Fine interlath austenite exhibits the highest stability against strain-induced martensitic transformation [61, 62]. Furthermore, the adjacent $\alpha^{\prime}$-martensite prevents them from noticeable straining during tensile test. Apart from the morphology, small austenitic regions, especially interlath austenite with a large interfacial area with the surrounding $\alpha^{\prime}$-martensite, experiences a more significant interstitial enrichment during partitioning.

Figure 2.26 shows the inverse pole figures (IPF) of austenite and $\alpha^{\prime}$-martensite phases in the AMC Cr19NC14.16 steel tested at RT. Figure 2.26a reveals the presence of two interdendritic austenitic regions marked by ellipses, which were only partially transformed into $\alpha^{\prime}$-martensite, indicating their superior austenite stability compared to the surrounding dendritic regions. The strong variant selection for the straininduced $\alpha^{\prime}$-martensite within the marked areas in Fig. 2.26b distinguishes this type 

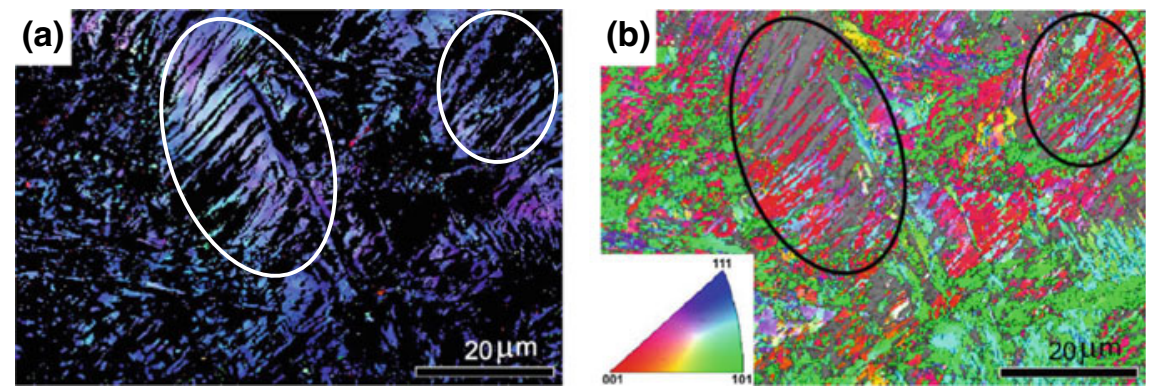

Fig. 2.26 IPF maps of (a) austenite and (b) $\alpha^{\prime}$-martensite in AMC Cr15NC12.16 tested at RT with tensile direction vertical in the plane of view [27]. Colors indicate crystal directions horizontal in the plane of view

of $\alpha^{\prime}$-martensite from as-quenched $\alpha^{\prime}$-martensite, which often consists of a larger number of $\alpha^{\prime}$-martensite variants.

\subsubsection{QDP Processing of Cr19NC14.16 Steel}

$f_{\alpha^{\prime}}$ evolutions during tensile testing at $-40{ }^{\circ} \mathrm{C}$ of the solution annealed $\mathrm{Cr} 19 \mathrm{NC} 14.16$ steel were quantified by in situ and ex situ magnetic measurements. As shown in Fig. 2.27a, both types of results are in reasonable agreement. Using these data, the coefficients $\alpha$ and $\beta$ in the equation proposed by Olson and Cohen for the evolution of

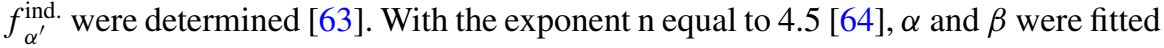
to be 7.49 and 2.09, respectively. Engineering strains of 0.15 and 0.25 , associated with 25 and 56 vol\% strain-induced $\alpha^{\prime}$-martensite, respectively, were selected for the pre-straining of the solution annealed $\mathrm{Cr} 19 \mathrm{NC} 14.16$ steel at $-40{ }^{\circ} \mathrm{C}$. The two QDP steels are accordingly denoted as QDP_15\% PS and QDP_25\% PS. The pre-strained
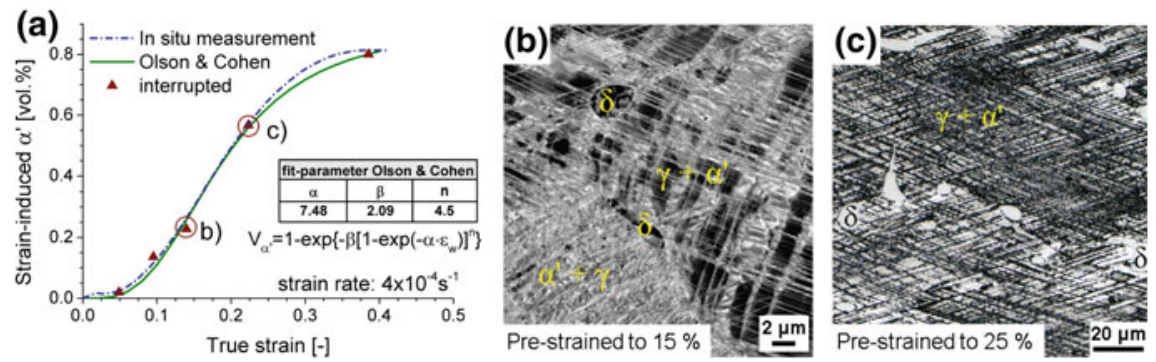

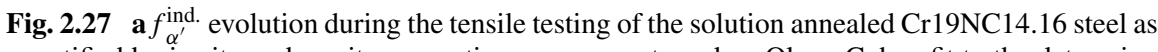
quantified by in situ and ex situ magnetic measurements and an Olson-Cohen fit to the data using the listed fitting parameters; $\mathbf{b}, \mathbf{c}$ ECC images corresponding to engineering strains of 0.15 and 0.25 [28] 

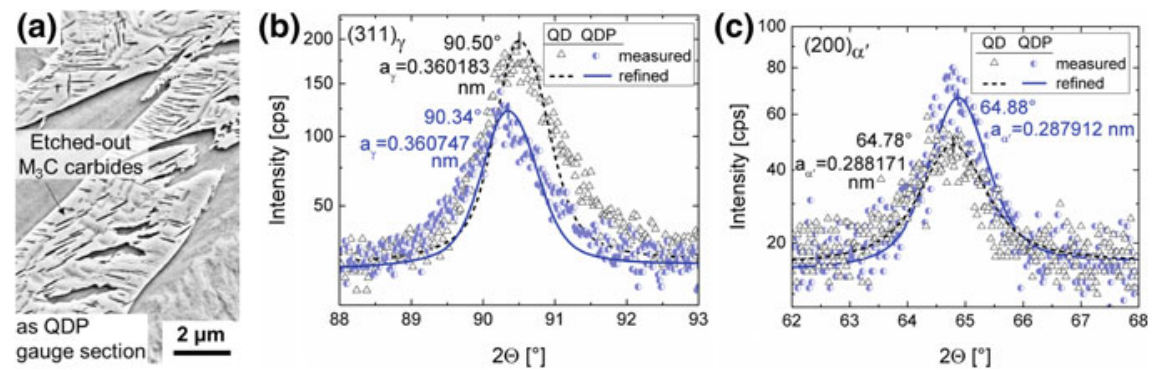

Fig. 2.28 a SEM image of electrolytically-etched $\alpha^{\prime}$-martensite in the final microstructure of the QDP_25\% PS Cr19NC14.16 steel; $\mathbf{b}(311)_{\gamma}$ and $\mathbf{c}(200)_{\alpha^{\prime}}$ peak profiles before and after partitioning [28]

microstructures are shown in Fig. 2.27b, c. In both conditions, a high density of slip bands are visible on multiple sets of $\{111\}$ glide planes with $\alpha^{\prime}$ martensite present within the bands and at their intersections.

Subsequent to partitioning, $\mathrm{M}_{3} \mathrm{C}$ carbides also formed in the $\alpha^{\prime}$-martensite phase of the QDP AMC Cr19NC14.16 steel (Fig. 2.28a). According to (311) $)_{\gamma}$ peak profiles, the interstitial content partitioned into the austenite is estimated to be $0.28 \mathrm{wt} \%$ for the QDP_25\% PS (Fig. 2.28b). Concurrently, the depletion of interstitial contents in $\alpha^{\prime}$-martensite results in the shift of its (200) $\alpha_{\alpha^{\prime}}$ peak to a higher angle (Fig. 2.28c).

In Fig. 2.29, the stress-strain curves of the AMC Cr19NC14.16 steel are compared with those in the solution annealed condition (quenched to RT). Due to the absence of $\alpha^{\prime}$-martensite formation during tensile tests, the solution annealed steel provides a generally low tensile strength, except at $-40{ }^{\circ} \mathrm{C}$. TE of the solution annealed steel ranges from 44 to $73 \%$. With the introduction of $\alpha^{\prime}$-martensite and a subsequent partitioning, tensile strength of the AMC Cr19NC14.16 steel is clearly enhanced at the expense of tensile elongation. The premature failure of QDP_15\% PS at 60 and $100{ }^{\circ} \mathrm{C}$ is associated with severe localized deformation in the transition zone from gauge section to the grip section of tensile specimens as shown in Fig. 2.30a. Based on magnetic measurements, with an applied pre-strain of $15 \%$, strain-induced $\alpha^{\prime}$ martensite only formed in the gauge section, while the transition and the grip sections retained a $\gamma-\delta$ microstructure. The absence of $\alpha^{\prime}$-martensitic constituent provided no opportunity to enhance austenite stability by interstitial partitioning. Furthermore, as shown in Fig. 2.19a for the solution annealed condition, it is expected that the QDP steel exhibits a pronounced TWIP effect in the transition area at $60{ }^{\circ} \mathrm{C}$, leading to a facilitated localized deformation and an early fracture. In contrast, the heavier pre-straining in QDP_25\% PS caused strain-induced $\alpha^{\prime}$-martensite formation even in the gauge to grip transition zone (Fig. 2.30b). This enabled interstitial enrichment of austenite in such regions during partitioning. The associated strengthening and the enhancement of austenite stability in such regions inhibited localized deformation and premature failure of the QDP_25\% PS steel at 60 and $100{ }^{\circ} \mathrm{C}$. Compared to Q\&P Cr15NC12.16, the work hardening rate of QDP_25\% PS is smaller as shown in Fig. 2.29c. Its negligible work hardening can be explained on one hand by the absence 

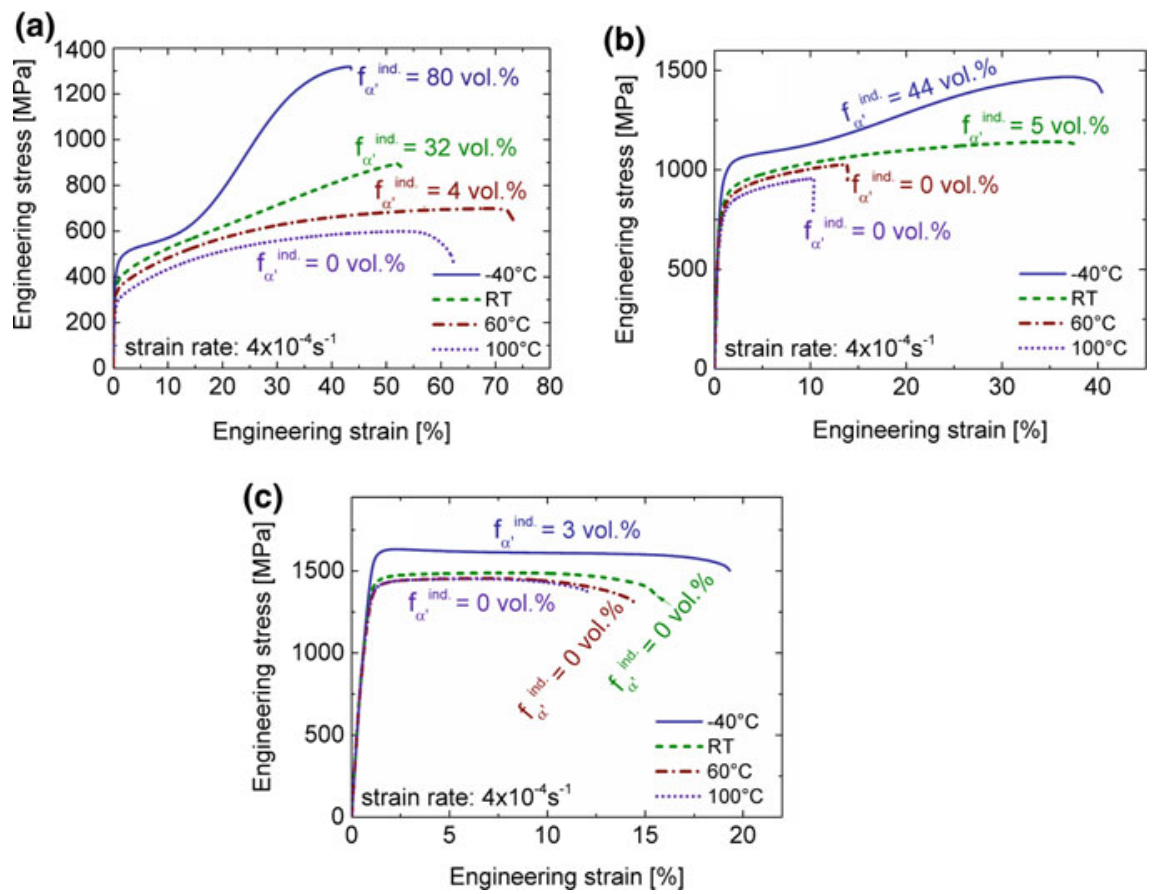

Fig. 2.29 Stress-strain curves of Cr19NC14.16 steel in various conditions [19, 28]: a Solution annealed and quenched to RT; b QDP_15\% PS; c QDP_25\% PS

Fig. 2.30 Tensile specimens of a QDP_15\% PS tested at $60{ }^{\circ} \mathrm{C}[19]$ and b QD_25\% PS tested at $60^{\circ} \mathrm{C}$ with $f_{\alpha^{\prime}}^{\text {ind. }}$ at different areas

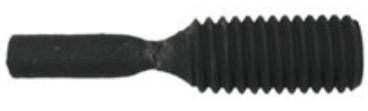

(a) QDP_15 \% PS

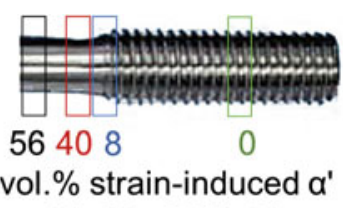

(b) QD_25\% PS

of $f_{\alpha^{\prime}}^{\text {ind. }}$ and on the other hand by the recovery of SFs during partitioning. They were generated at $-40{ }^{\circ} \mathrm{C}$ in the course of pre-straining and then narrowed/annihilated at $450{ }^{\circ} \mathrm{C}$ due to raised SFE [65]. Such constricted SFs in the pre-existing deformation bands can widen upon further deformation at lower temperatures without necessity of activating new glide systems.

The phase fraction evolution and the mechanical properties of AMC Cr19NC14.16 steel are summarized in Fig. 2.31. $M_{d}$ temperature decreases from $70{ }^{\circ} \mathrm{C}$ in the solution annealed condition to nearly RT and $-40{ }^{\circ} \mathrm{C}$ after QDP_15\% PS and QDP_25\% PS processing, respectively. The lower $M_{d}$ of the latter can be attributed to the higher interstitial enrichment in the austenite due to a larger $f_{\alpha^{\prime}}^{\text {ind. }}$. 
(a)

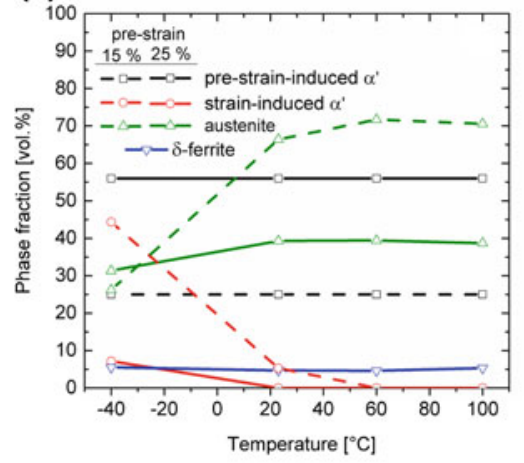

(b)

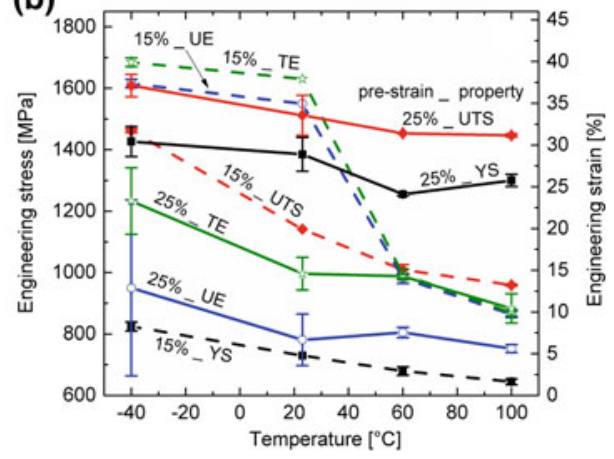

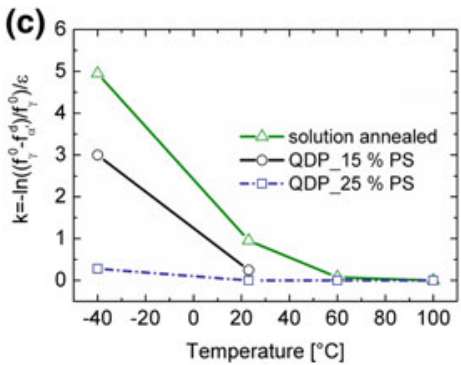

Fig. 2.31 a Evolution of phase fractions, $\mathbf{b}$ mechanical properties and $\mathbf{c}$ calculated $k$ parameter of AMC Cr19NC14.16 tested at various temperatures [19]. Due to the localized deformation in the gauge to grip transition zone, $k$ values for QDP_15\% PS at 60 and $100{ }^{\circ} \mathrm{C}$ are not given. $k$ values for the solution annealed condition are shown for comparison

Both steels exhibit excellent tensile strength, which increases at lower temperature. QDP_15\% PS steel provides a YS of 644-824 MPa and a UTS of 960$1461 \mathrm{MPa}$, while QDP_25\% PS steel exhibits a YS of 1300-1426 MPa and a UTS of 1446-1608 MPa. Similar to the Q\&P-processed AMC Cr15NC12.16 steel, a concurrent enhancement of tensile strength and elongation at temperatures below $M_{d}$ was observed. This can be explained by the occurrence of elemental segregation during solidification and the inhomogeneous interstitial enrichment of austenite in the partitioning step. The mechanical stability of austenite, expressed in terms of the $k$-parameter is shown in Fig. 2.31c. Due to the occurrence of localized deformation in the transition zone, this parameter was not determined for the QDP_15\% PS steel tested at 60 and $100{ }^{\circ} \mathrm{C}$. As a result of the interstitial enrichment, the mechanical stability of austenite was significantly improved after QDP Processing.

The fracture surfaces of QDP_25\% PS tested at RT and $-40{ }^{\circ} \mathrm{C}$ are illustrated in Fig. 2.32. Both specimens exhibit a ductile cup-and-cone fracture surface (Figs. 2.32a, d). At RT, intensive dimples formed often around inclusions (Fig. 2.32b), especially around $\mathrm{Al}_{2} \mathrm{O}_{3}$ inclusions based on the EDS analysis. Parallel aligned dendrites were observed, such as those hundreds $\mu \mathrm{m}$ long marked by ellipses in Fig. 2.32b. Their longitudinal direction denotes their growth direction during solidification and reveals the thickness direction of the cast ingot, namely the heat 

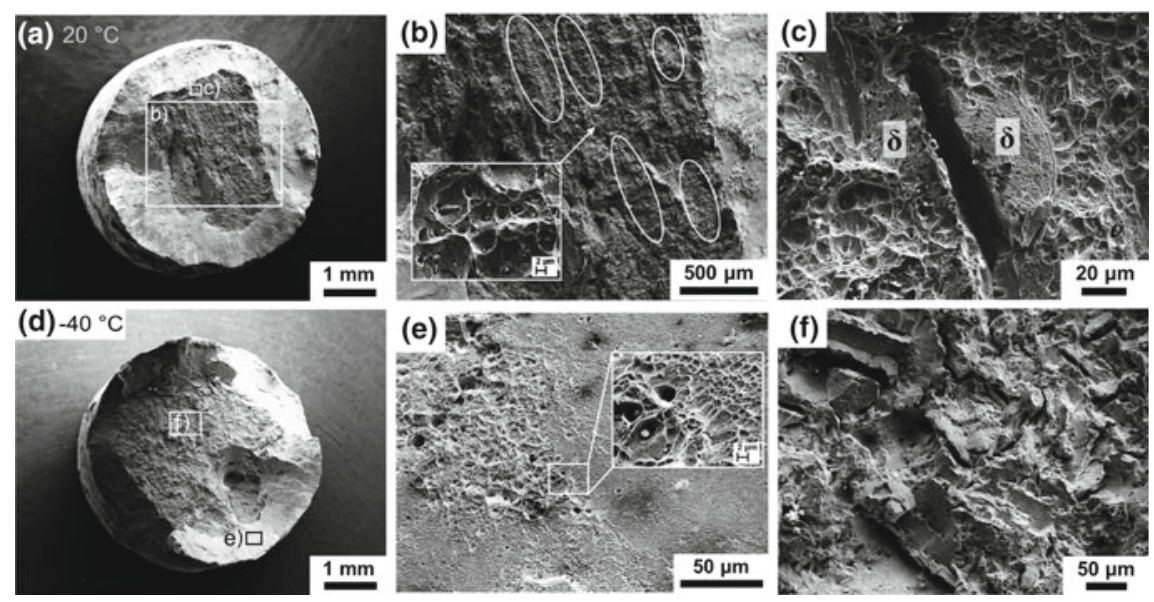

Fig. 2.32 Fracture surfaces of QDP_25\% PS tested at RT (a-c) and at $-40{ }^{\circ} \mathrm{C}(\mathbf{d}-\mathbf{f})$ [28]: a, $\mathbf{d}$ overview of the entire fracture surface; $\mathbf{b}-\mathbf{c}, \mathbf{e}-\mathbf{f}$ magnified view of the regions marked by rectangles in $\mathbf{a}, \mathbf{b}$. $\mathbf{b}, \mathbf{e}$ dimples formation; $\mathbf{c}, \mathbf{f}$ decohesion

dissipation direction (Fig. 2.8). Material decohesion was only observed occasionally in the central fracture region. As shown in Fig. 2.32c, the separation initiates very likely within $\delta$-ferrite or at prior austenite/ferrite boundaries. At $-40{ }^{\circ} \mathrm{C}$, pronounced formation of dimples with various sizes was observed as well (Fig. 2.32e). Compared to the test at RT, cracks due to the decohesion at grain boundaries were more obvious as exemplified in Fig. 2.32f. This is to some extent due to the higher tensile elongation at $-40{ }^{\circ} \mathrm{C}$. In other words, the damage tolerance evaluated by the ductility was even higher than at RT, which can be ascribed to the enhanced glide planarity of austenite.

\subsubsection{Conclusions for the $3^{\text {rd }}$ Generation Steels}

The $3^{\text {rd }}$ generation steels were developed by treating $\mathrm{Cr} 15 \mathrm{NC} 12.16$ and Cr19NC14.16 steels with tailored Q\&P processing. The aim was to improve the tensile strength, especially YS, without significant loss of ductility. Following conclusions can be drawn:

1. The processing parameters and mechanical properties at RT of AMC Cr15NC12.16 and $\mathrm{Cr} 19 \mathrm{NC} 14.16$ steels are presented in Table 2.8.

2. After partitioning at $450{ }^{\circ} \mathrm{C}$ for $3 \mathrm{~min}, \mathrm{M}_{3} \mathrm{C}$ carbides formed in $\alpha^{\prime}$-martensite, leading to an interstitial loss that competed with the interstitial enrichment in the austenite.

3. The high fractions of $\alpha^{\prime}$-martensite strengthened by $\mathrm{M}_{3} \mathrm{C}$ carbides enhanced YS significantly. The YS exceeded $900 \mathrm{MPa}$ for the Q\&P Cr15NC12.16 and 
Table 2.8 Summarized processing parameters and mechanical properties at RT of AMC Cr15NC12.16 and Cr19NC14.16 steels

\begin{tabular}{l|l|l|l}
\hline Steels & Cr15NC12.16 & Cr19NC14.16 \\
\hline $\begin{array}{l}\text { Method to create } \\
\alpha^{\prime} \text {-martensite }\end{array}$ & Quench to $-130{ }^{\circ} \mathrm{C}$ & $\begin{array}{l}15 \% \text { pre-strain at } \\
-40{ }^{\circ} \mathrm{C}\end{array}$ & $\begin{array}{l}25 \% \text { pre-strain at } \\
-40{ }^{\circ} \mathrm{C}\end{array}$ \\
\hline $\begin{array}{l}f_{\alpha^{\prime}} \text { prior to } \\
\text { partitioning }(\mathrm{vol} \%)\end{array}$ & 58 & 25 & 56 \\
\hline YS at RT $(\mathrm{MPa})$ & 1013 & 730 & 1385 \\
\hline UTS at RT $(\mathrm{MPa})$ & 1550 & 1141 & 1510 \\
\hline TE at RT $(\%)$ & 22 & 38 & 15 \\
\hline UTS $\times$ TE $(\mathrm{GPa} \%)$ & 34.1 & 43.4 & 22.7 \\
\hline
\end{tabular}

QDP_25\% PS steels. The latter reaches even $1426 \mathrm{MPa}$ due to the additional work hardening in the course of pre-straining.

4. After partitioning, both strength and ductility increase at lower temperatures. The enhanced ductility in spite of the formation of strain-induced $\alpha^{\prime}$-martensite is attributed to the chemical composition inhomogeneities, which originated from the solidification and was reinforced during the Q\&P processing.

5. Deformation was mostly accommodated by the planar glide of dislocations in the austenite phase of partitioned steels. In QDP steels, the constriction of the pre-straining-induced SFs in the subsequent partitioning step and their easy separation during further deformation at lower temperatures excludes the need for activating new glide system. This leads to a negligible work hardening rate.

\subsection{Conclusions}

This chapter focuses on the development of cast CrMnNi stainless steels exhibiting excellent strength-ductility combination with the aid of TRIP/TWIP effect. Figure 2.33 summarizes the mechanical properties of the three generation steels presented in this chapter. The $1^{\text {st }}$ generation steels include interstitial-free 16-7$3 / 6 / 9$ steels with SFEs ranging from $10-22 \mathrm{mJm}^{-2}$. Regardless of their coarse cast microstructures, both 16-7-6/9 steels provided an excellent product of UTS and TE of approximately $40 \mathrm{GPa} \%$ due to the dynamic Hall-Petch effect by the formation of deformation bands, twins and strain-induced $\alpha^{\prime}$-martensite. Nevertheless, their YS was mostly below $400 \mathrm{MPa}$ due to the almost fully austenitic microstructures. Therefore, interstitially-alloyed steels Cr15NC10.X and Cr19NC15.X were produced for the $2^{\text {nd }}$ generation steels, aiming at solid solution strengthening, second phase strengthening by introducing as-quenched $\alpha^{\prime}$-martensite, and precipitation hardening. Within the studied $\mathrm{C}$ content range of $0.05-0.25 \mathrm{wt} \%$, YS decreased and TE increased at higher $\mathrm{C}$ contents in the $\mathrm{Cr} 15 \mathrm{NC} 10 . \mathrm{X}$ steel series. Accordingly, YS in excess of $600 \mathrm{MPa}$ was mostly accompanied by a TE of less than $10 \%$. The 


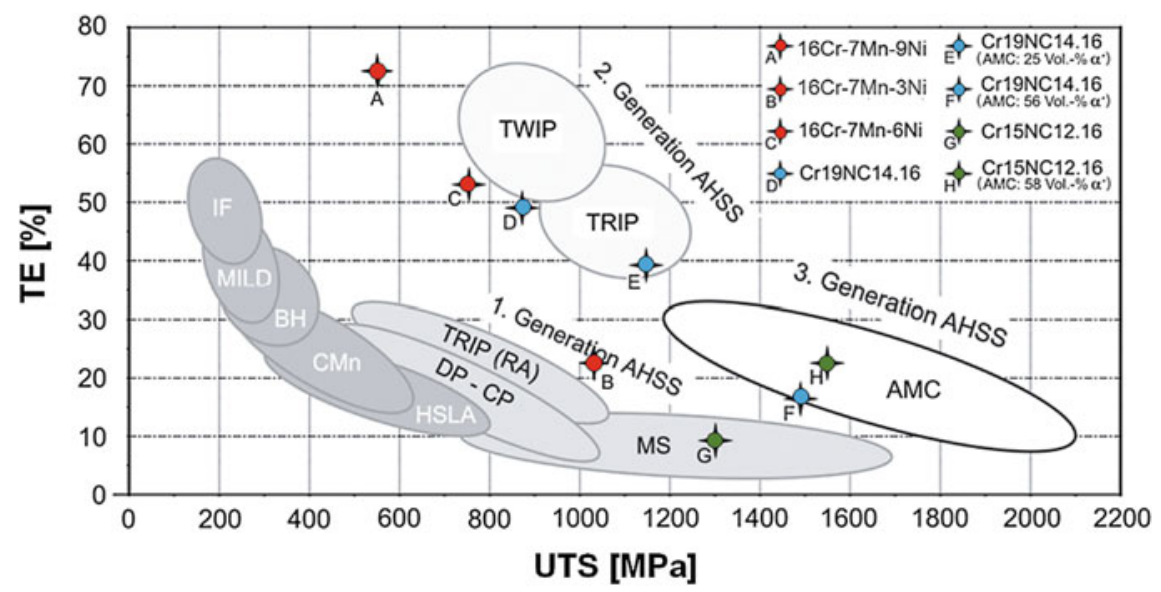

Fig. 2.33 Mechanical properties of steels presented in this chapter compared to those of advanced high strength steels (AHSS) [19]

enhanced ductility and reduced strength at higher $\mathrm{C}$ contents was due to the increase in the fraction and stability of austenite. Cr19NC15.X steel series with almost fully austenitic microstructures exhibited excellent ductility but YS below $450 \mathrm{MPa}$. To further enhance the YS, Q\&P and QDP processing were applied to the Cr15NC12.16 and $\mathrm{Cr} 19 \mathrm{NC} 14.16$ steels, respectively, to develop the $3^{\text {rd }}$ generation steels. For the former, 58 vol\% $\alpha^{\prime}$-martensite was created by quenching from $1150{ }^{\circ} \mathrm{C}$ to RT and then to $-130{ }^{\circ} \mathrm{C}$, while for the latter with an $\mathrm{M}_{\mathrm{s}}$ temperature below $-196{ }^{\circ} \mathrm{C}, 25$ and $56 \mathrm{vol} \% \alpha^{\prime}$-martensite were introduced by tensile straining at $-40{ }^{\circ} \mathrm{C}$ to strains of $15 \%$ and $25 \%$. Partitioning was then performed at $450{ }^{\circ} \mathrm{C}$ for $3 \mathrm{~min}$. Due to the high fractions of $\alpha^{\prime}$-martensite with embedded fine $\mathrm{M}_{3} \mathrm{C}$ carbides, AMC $\mathrm{Cr} 15 \mathrm{NC} 12.16$ steel and QDP_25\% PS exhibited excellent YS above $900 \mathrm{MPa}$ in the temperature range of -40 to $200{ }^{\circ} \mathrm{C}$. The QDP_25\% PS steel exhibited an especially high YS of $1426 \mathrm{MPa}$ at $-40{ }^{\circ} \mathrm{C}$ owing to the additional work hardening in the course of pre-straining. The chemical segregation generated during solidification is intensified during Q\&P processing, which results in an enhanced ductility even at tensile temperatures below $M_{d}$ temperature where deformation-induced $\alpha^{\prime}$-martensitic transformation takes place. As indicated in Table 2.8, the product of UTS and TE at RT reaches 34, 43 and $23 \mathrm{GPa} \%$ for Q\&P Cr15NC12.16, QDP Cr19NC14.16 with 15\% and $25 \%$ pre-straining, respectively.

Acknowledgements The authors would like to thank Dr. A. Jahn for the research on the $1^{\text {st }}$ generation steels. Sincere thanks are due to the colleagues at the Institute of Iron and Steel Technology (IEST) and the Institute of Materials Science (IWW) for their support and assistance on the experiments: Dr. R. Rahimi, Ms. C. Ullrich and Dr. C. Schimpf for the SEM, ECCI and XRD measurements; Dr. M. Motylenko for the TEM examinations; Mr. M. Hauser for the tensile tests with in situ magnetic measurements; Dr. T. Kreschel und Mr. G. Franke for the heat treatments; Mrs. G. Schubert for the dilatometry experiments and hardness tests; Mr. P. Neuhold for producing the steels; Mr. G. Schade for the tensile tests; Mrs. I. Grahl and Mrs. J. Kreschel for the metallographic 
sample preparation and light optical microscope observations; Mr. M Block for the machining of specimens; and all the student assistants for the magnetic measurements.

This work was funded by the Deutsche Forschungsgemeinschaft (DFG, German Research Foundation) - Projektnummer 54473466-SFB 799 under the subproject A2. The financial support is gratefully acknowledged. The authors would also like to thank Prof. P. R. Scheller, the previous director of IEST, for his support on preparing the A2 subproject proposal. Special thanks are extended to all the colleagues from SFB 799 for the valuable and fruitful scientific discussions.

\section{References}

1. M. Naghizadeh, H. Mirzadeh, Metall. Mat. Trans. A 47, 4210 (2016)

2. S.H. Bak, M.A. Abro, D.B. Lee, Metals 6, 169 (2016)

3. E. Polatidis, W.-N. Hsu, M. Šmíd, T. Panzner, S. Chakrabarty, P. Pant, H. Van Swygenhoven, Scr. Mater. 147, 27 (2018)

4. I. Karaman, H. Sehitoglu, Y.I. Chumlyakov, H.J. Maier, JOM 54, 31 (2002)

5. L. Kaufman, M. Cohen, Prog. Met. Phys. 7, 165 (1958)

6. G.B. Olson, M. Cohen, Metall. Trans. A 7, 1897 (1976)

7. L. Rémy, A. Pineau, B. Thomas, Mater. Sci. Eng. 36, 47 (1978)

8. F. Lecroisey, B. Thomas, Phys. Stat. Sol. (a) 2, K217 (1970)

9. T. Yonezawa, K. Suzuki, S. Ooki, A. Hashimoto, Metall. Mat. Trans. A 44, 5884 (2013)

10. M. Wendler, A. Weiß, L. Krüger, J. Mola, A. Franke, A. Kovalev, S. Wolf, Adv. Eng. Mater. 15, $558(2013)$

11. A. Dumay, J.-P. Chateau, S. Allain, S. Migot, O. Bouaziz, Mater. Sci. Eng. A 483, 184 (2008)

12. A. Saeed-Akbari, L. Mosecker, A. Schwedt, W. Bleck, Metall. Mat. Trans. A 43, 1688 (2012)

13. D. Fahr, Dissertation, University of California, 1969

14. S. Martin, S. Wolf, U. Martin, L. Krüger, Solid State Phenom. 172-174, 172 (2011)

15. B.C. De Cooman, O. Kwon, K.-G. Chin, Mater. Sci. Technol. 28, 513 (2012)

16. H.-J. Kestenbach, Philos. Mag. 36, 1509 (1977)

17. M. Pozuelo, J.E. Wittig, J.A. Jiménez, G. Frommeyer, Metall. Mat. Trans. A 40, 1826 (2009)

18. J. Mola, in Austenitic Stainless Steels-New Aspects, eds. by W. Borek, T. Tanski, Z. Brytan (InTech, 2017), pp. 7-28

19. M. Wendler, Dissertation, Technische Universität Bergakademie Freiberg, 2017

20. R.E. Schramm, R.P. Reed, Metall. Trans. A 6, 1345 (1975)

21. R. E. Stoltz, J. B. Vander Sande, Metall. Trans. A 11, 1033 (1980)

22. T.-H. Lee, E. Shin, C.-S. Oh, H.-Y. Ha, S.-J. Kim, Acta Mater. 58, 3173 (2010)

23. R.M. Latanision, A.W. Ruff, Metall. Trans. 2, 505 (1971)

24. F. Lecroisey, A. Pineau, Metall. Mat. Trans. B 3, 391 (1972)

25. F. Abrassart, Metall. Trans. 4, 2205 (1973)

26. L. Rémy, A. Pineau, Mater. Sci. Eng. 26, 123 (1976)

27. M. Wendler, C. Ullrich, M. Hauser, L. Krüger, O. Volkova, A. Weiß, J. Mola, Acta Mater. 133, 346 (2017)

28. M. Wendler, M. Hauser, M. Motylenko, J. Mola, L. Krüger, O. Volkova, Adv. Eng. Mater. 21, 1800571 (2019)

29. M. Wendler, M. Hauser, E.F. Sandig, O. Volkova, Metall. Mat. Trans. B 49, 581 (2018)

30. A. Jahn, A. Kovalev, A. Weiß, P.R. Scheller, Steel Res. Int. 82, 1108 (2011)

31. A. Jahn, A. Kovalev, A. Weiß, S. Wolf, L. Krüger, P.R. Scheller, Steel Res. Int. 82, 39 (2011)

32. A. Weiss, H. Gutte, M. Radtke, P. Scheller, WO/2008/009722 (25 January 2008)

33. Q.-X. Dai, A.-D. Wang, X.-N. Cheng, X.-M. Luo, Chin. Phys. (Overseas Edition) 11, 596 (2002)

34. A. Jahn, Dissertation, Technische Universität Bergakademie Freiberg, 2012 
35. R. Rahimi, C. Ullrich, V. Klemm, D. Rafaja, B.C. De Cooman, H. Biermann, J. Mola, Mater. Sci. Eng., A 649, 301 (2016)

36. Y. Maehara, Y.S.U. Tani, K. Gunti, Trans. ISIJ 25, 8 (1985)

37. A. Weiss, M. Wendler, H. Gutte, H. Biermann, Int. J. Foundry Res. 65, 2 (2013)

38. Y. Kobayashi, H. Todoroki, N. Shiga, T. Ishii, ISIJ Int. 52, 1601 (2012)

39. M. Wendler, M. Hauser, O. Fabrichnaya, L. Krüger, A. Weiß, J. Mola, Mater. Sci. Eng. A 645, $28(2015)$

40. J.-O. Andersson, T. Helander, L. Höglund, P. Shi, B. Sundman, Calphad 26, 273 (2002)

41. M. Hauser, M. Wendler, O. Fabrichnaya, O. Volkova, J. Mola, Mater. Sci. Eng. A 675, 415 (2016)

42. Y.S. Zhang, X. Lu, X. Tian, Z. Qin, Mater. Sci. Eng. A 334, 19 (2002)

43. A. Sato, E. Chishima, Y. Yamaji, T. Mori, Acta Metall. 32, 539 (1984)

44. G. Ghosh, V. Raghavan, Mater. Sci. Eng. 80, 65 (1986)

45. O.N. Mohanty, Mater. Sci. Eng. B 32, 267 (1995)

46. P.J. Brofman, G.S. Ansell, Metall. Trans. A 9, 879 (1978)

47. J.W. Fu, Y.S. Yang, J.J. Guo, W.H. Tong, Mater. Sci. Technol. 24, 941 (2008)

48. T. Koseki, M.C. Flemings, Metall. Mat. Trans. A 27, 3226 (1996)

49. J. Mola, M. Wendler, A. Weiß, B. Reichel, G. Wolf, B.C.D. Cooman, Metall. Mat. Trans. A 46, 1450 (2015)

50. J. Speer, D.K. Matlock, B.C. De Cooman, J.G. Schroth, Acta Mater. 51, 2611 (2003)

51. R. Eckner, L. Krüger, C. Ullrich, M. Wendler, O. Volkova, Int. J. Fract. 215, 139 (2019)

52. J. Mola, B.C.D. Cooman, Metall. Mat. Trans. A 44, 946 (2013)

53. Q. Huang, C. Schröder, H. Biermann, O. Volkova, J. Mola, Steel Res. Int. 87, 1082 (2016)

54. J.G. Speer, F.C. Rizzo Assunção, D.K. Matlock, D.V. Edmonds, Mater. Res. 8, 417 (2005)

55. M. Hauser, M. Wendler, S.G. Chowdhury, A. Weiß, J. Mola, Mater. Sci. Technol. 31, 1473 (2015)

56. J. Ågren, Scr. Mater. 20, 1507 (1986)

57. H. Oettel, H. Schumann, Metallografie: mit einer Einführung in die Keramografie (Wiley, 2011)

58. L. Yuan, D. Ponge, J. Wittig, P. Choi, J.A. Jiménez, D. Raabe, Acta Mater. 60, 2790 (2012)

59. T. Minemura, A. Inoue, T. masumoto, Trans. ISIJ 21, 649 (1981)

60. K.-I. Sugimoto, M. Kobayashi, S.I. Hashimoto, Metall. Mater. Trans. A 23, 3085 (1992)

61. A. Rosen, R. Jago, T. Kjer, J. Mater. Sci. 7, 870 (1972)

62. K. Nohara, Y. Ono, N. Ohashi, Tetsu-to-Hagane 63, 772 (1977)

63. G.B. Olson, M. Cohen, MTA 6, 791 (1975)

64. J. Talonen, H. Hänninen, P. Nenonen, G. Pape, Metall. Mat. Trans. A 36, 421 (2005)

65. Q. Huang, B.C.D. Cooman, H. Biermann, J. Mola, Metall. Mat. Trans. A 47, 1947 (2016)

Open Access This chapter is licensed under the terms of the Creative Commons Attribution 4.0 International License (http://creativecommons.org/licenses/by/4.0/), which permits use, sharing, adaptation, distribution and reproduction in any medium or format, as long as you give appropriate credit to the original author(s) and the source, provide a link to the Creative Commons license and indicate if changes were made.

The images or other third party material in this chapter are included in the chapter's Creative Commons license, unless indicated otherwise in a credit line to the material. If material is not included in the chapter's Creative Commons license and your intended use is not permitted by statutory regulation or exceeds the permitted use, you will need to obtain permission directly from the copyright holder. 